\title{
Introducción acerca de las implicaciones del Estado de Derecho en su relación con el concepto de responsabilidad patrimonial ${ }^{(* *)}$
}

\section{Introduction about the implications of the Rule of Law in its relation to the concept of asset liability}

\begin{abstract}
Resumen: El autor realiza una indagación de la evolución del Estado como un producto de lo que se conoce como Estado Moderno. El estudio se centra en los ámbitos histórico y jurídico del concepto de Estado de Derecho como producto del Estado Moderno, para analizar la construcción e institucionalización de un sistema de responsabilidad patrimonial del Estado

Palabras Claves: Estado Absoluto - Estado de Derecho - Estado de Bienestar - Estado Neoliberal - Responsabilidad Patrimonial

Abstract: The author makes an inquiry into the evolution of the State as a product of what is known as the Modern State. The study focuses on the historical and legal aspects of the concept of the Rule of Law as a product of the Modern State, in order to analyze the construction and institutionalization of a system of asset liability of the State.
\end{abstract}

Keywords: Absolute State - Rule of Law - Welfare State - Neoliberal State - Asset Liability

\section{La génesis del Estado moderno y sus implicaciones en el desarrollo del concepto de responsabilidad patrimonial}

La forma como se relacionan los individuos y la organización abstracta que concentra el poder político y las decisiones han variado en los

${ }^{*}$ ) Doctor en Derecho por la Universidad Nacional Autónoma de México. Profesor-Investigador de la Facultad de Derecho y Criminología de la Universidad Autónoma de Nuevo León. Miembro del Sistema Nacional de Investigadores del CONACYT. Correo electrónico: gerardorodriguezmx@yahoo.com.mx

${ }^{* *}$ Doctora en Derecho con orientación en Derecho Constitucional y Gobernabilidad por la Facultad de Derecho y Criminología de la Universidad Autónoma de Nuevo León. Magíster en Derecho con orientación en Derecho Constitucional y Gobernabilidad por la Universidad Autónoma de Nuevo León. Ha sido profesora de Derecho Constitucional y Teoría General del Estado en la misma Facultad. Correo electrónico: garzahernandez.taly@gmail.com

$\left.{ }^{(* *}\right)$ Nota del Editor: El artículo fue recibido el 10 de octubre de 2016 y aprobada su publicación el 12 de diciembre del mismo año. 


\section{Introducción acerca de las implicaciones del Estado de derecho en su relación con el concepto de responsabilidad patrimonial Introduction about the implications of the Rule of Law in its relation to the concept of asset liability}

distintos tiempos históricos, y las formas que han adquirido estas interacciones han sido estudiadas cada una por su método, por la Ciencia Política y el Derecho, particularmente, por el Derecho Constitucional. El Estado ha sido pues una realidad histórica que se ha apreciado en una diversidad de "contextos políticos", por utilizar un término que Skinner concede a lo que se deriva de la existencia del término Estado y de sus equivalentes, que son, por supuesto, distintos, ya que por una parte se observan diferentes denominaciones lingüísticas (Skinner 2003, 23), y la condición que los hombres guardaban en proporción de esta configuración se predetermina una "situación jurídica" (Skiner 2003, 23), en la que no pasa desapercibida, lo señala Skinner y aunque parezca obvio lo manifestamos: los gobernantes asumían ciertas prerrogativas, que Skinner describe como: "disfrutando de un distintivo" (Skinner 2003, 23).

Indudablemente, estas primeras consecuencias de la relación establecida entre el Estado, manifestada por medio de los órganos que individualizan su correspondiente soberanía abstracta, atribuían una cierta condición de superioridad a los órganos estatales y a sus detentadores, esto es, los individuos a quienes les corresponde encargarse de la vida política. Esta situación no es menor, ya que incide en la forma como se administrarán los asuntos públicos; en la integración de la clase gobernante; el desarrollo de los criterios de competencia para los cargos públicos; cómo se van generando los acuerdos y las reparticiones en la división del trabajo público y privado; la conformación del interés público y de sus límites con el interés privado, y la construcción del concepto de responsabilidad política, en estos aspectos se inscriben los estudios sobre la burocracia, la tecnocracia y la democracia electoral; esta última constituye en sí solo un capítulo de las vastas implicaciones políticas y morales que tiene la discusión sobre las relaciones entre el poder político y el Estado y sus consecuencias sobre la vida humana.

Una vez que realizamos unas consideraciones básicas a la luz de las transformaciones del Estado podemos asentir en que el Estado es, fundamentalmente, un "fenómeno común" de la historia y de la naturaleza humana. Su estudio científico se ha plasmado desde diversas disciplinas, la del Derecho Público, la de la Teoría del Estado, la perspectiva sociológica y la de la sociología jurídica. En atención al origen del término, la voz Estado proviene del latín status. La palabra fue utilizada de forma indistinta y gradual para hacer frente a diferentes manifestaciones de estas realidades políticas. Skinner rememora como la utilización de esta voz se rastrea durante el siglo XIV, inclusive, con equivalentes en lenguas nativas europeas (Skinner 2003, 23); por tanto, esto se encuadra con las formas de gobierno (Bobbio 1975, 10-11). En la inteligencia de que esta voz se asociaba a las formas de gobierno, regímenes dominantes y la posición del gobernante ${ }^{(1)}$. La evolución y la transfiguración que hacen notorio lo que deseamos manifestar en la construcción del sistema de responsabilidad patrimonial muy posterior converge precisamente en esto, la traslación, el giro, de un concepto de Estado centrado en la posición dominante del gobernante o del régimen, en uno centrado en la comunidad de derechos que tendría su más grande y primera manifestación con el concepto de responsabilidad política, tan característico como institución de los sistemas parlamentarios.

Obviamente, en este estudio, el ámbito histórico y jurídico que nos interesa analizar lo constituye el concepto de Estado de Derecho como producto del Estado moderno. Las implicaciones del concepto de Estado que sean ajenas al contexto histórico moderno exceden los alcances de una publicación como la que pretendemos formular ahora. Aunque sí es importante no pasar de largo y advertir que la dicotomía de los antiguos y modernos es importante, apelando al uso histórico de las tipologías de las formas de gobierno como lo

(1) Las acepciones con las cuales se identificaba el concepto primigenio de Estado en los albores del Estado moderno se encuentran en Skinner, Quentin. El nacimiento del Estado. Traducido por Mariana Gaiza (Ciudad Autónoma de Buenos Aires: Gorla, 2003), 31-2. 


\section{Luis Gerardo Rodríguez Lozano y Talia Garza Hernández}

podemos observar en un estudio de Norberto Bobbio, al cual remitimos a quien tenga interés en realizar una introspección que abunde en el concepto de la antigüedad del Estado (Bobbio 1975, 12-13), pero es en el Estado moderno en el que ocurre una transformación sustancial en relación al derecho y en esta etapa es en la que se centrará nuestra investigación ${ }^{(2)}$.

Las manifestaciones del Estado moderno no pueden desprenderse del análisis que surge en la evolución del pensamiento histórico y científico occidental hacia un modelo abstracto y que concierne a las organizaciones sociales. Porque las organizaciones sociales dependen de un orden social. Y en esto desempeñará un papel la evolución del propio concepto de institución. Webber determina que el orden puede revestir dos formas:

"Convención y derecho. En la convención, la validez del orden puede no ser aprobada por una minoría, se trata de un pacto que requiere del acuerdo de la contraparte. En el derecho puede ocurrir algo distinto y esa una de las características básicas de este sistema, porque se garantiza la validez del orden por medio del instrumento de la coacción que es ejercido por un grupo de individuos a los que se les ha transferido la capacidad de vigilar el cumplimiento del orden o en su defecto de ser sancionados si violentan el orden" (Weber 2002, 27).

Como se verá en el desarrollo de esta investigación, el Estado moderno corresponde a una ruptura con el pasado medieval y una reconfiguración de la soberanía. En el Estado moderno, también se reconfiguraron las nociones de las fuentes de autoridad y de legitimación del orden social y político (Weber 2002, 29). Es comprensible así que uno de los principales instrumentos de transformación lo constituya precisamente el orden representado por el Derecho. Al respecto, la validez legítima del orden estatuido puede ser, según Weber, tradicional, por creencia efectiva, por creencia racional con arreglo a valores y por legalidad (Weber 2002, 27).
Para Weber, la validez racional con arreglo a valores está representada por el derecho natural y en esto muestra un gran adelanto la figura de Weber: "Cualquiera que haya sido su limitación frente a sus pretensiones ideales, no puede negarse, sin embargo, el influjo efectivo y no insignificante de sus preceptos lógicamente deducidos sobre la conducta; preceptos que hay que separar tanto de los revelados como de los estatuidos o de los derivados del derecho tradicional" (Weber 2002, 30). En tal concepto, Weber reconoce que la forma de legitimidad basada en la legalidad es la más frecuente e, incluso, admite que es bastante antigua (Weber 2002, 27). Para Weber, aunque la legalidad es "corriente" por su uso no siempre suele ser aceptada por "unanimidad" en ocasiones puede ocurrir su acatamiento/obediencia por "sumisión", aun cuando estas deficiencias surgen en la constitución de esa forma de legitimidad, la legalidad supone unos instrumentos bastante meritorios: los procedimientos y las instituciones formales (Weber 2002, 30).

La transformación que supone en el Estado moderno la superación del orden medieval y del derecho medieval equivale a una superación del concepto medieval basado en el derecho natural y en la fuente de autoridad que residía en lo religioso. El Estado moderno se acompañará de una clase de derecho positivo, de un derecho individual, mientras que en el Estado moderno es el individuo a quien se le reconoce derechos y obligaciones; aunque la evolución fue asombrosa el cambio no fue sencillo, pues los Estados europeos profundizaron más en el orden de la legalidad.

(2) Véase Blandine Kriegel, The state and the rule of law. Transcrito por Marc A. LePain, Jeffrey C. Cohen (Princeton: Princeton University Press, 1995), 57. "The originality of modern political right and of the modern state under the rule of law lies in their distance from Roman law. In the twelfth century, recourse was had to the Roman models. This recourse was necessary so long as one was combating legal nihilism, desperately trying to replace military disorder with legal order, seeking to win acceptance of the legitimacy of the principle of law. Once the principle had been established, though, societies were ready to proceed to its application, to go from form to substance, to establish modern political right as a rule for the governance of free men and women, for the legal emancipation of the serfs, and for the securing of subjective rights". 


\section{Introducción acerca de las implicaciones del Estado de derecho en su relación con el concepto de responsabilidad patrimonial Introduction about the implications of the Rule of Law in its relation to the concept of asset liability}

Faustino Martínez expone el conflicto inmanente para la comprensión de la justicia:

"El orden jurídico se pone en movimiento. No tanto el inicio del conflicto, u orígenes más o menos remotos, como la solución del mismo es lo que preside el debate que conduce a ese veredicto final en aras de la justicia. Aparece así una idea capital, la de justicia, entendida como aquel cúmulo de principios que han de regir para determinar la calificación, primero, y la clasificación, después, de unos acontecimientos que nos circundan. La elaboración del concepto es decisiva, pues, eso somos: creadores de conceptos antes que narradores de sucesos" (Martínez 2010, 463).

Si en el régimen feudal, la fundamentación de la autoridad se representaba por la naturaleza (Bastida, Varela y Requejo $2008,111)$, encontrando en el derecho natural la fuente para la legitimación de la autoridad y del poder político; en el Estado moderno, la fundamentación de la autoridad siempre puede ser cuestionada, subyace un concepto materialista del orden político y del orden jurídico; para contextualizar añadimos una frase de Fioravanti:

“(...) si la constitución de los antiguos podía concebirse como un orden político ideal, al que tender prescriptivamente, la constitución medieval puede entenderse más bien como un orden jurídico dado a preservar, a defender frente a todos aquellos que pretendan introducir alteraciones arbitrarias en los equilibrios existentes (Fioravanti, 37)"

En el Estado moderno, la Constitución aparece como una técnica para la limitación del poder político que diferenciará al Estado moderno del régimen feudal y a la concepción del derecho de cada una de estas épocas. La progresiva evolución del derecho occidental se verá reflejada por conducto de los constitucionalismos, como procesos históricos, pero estos escenarios prominentes solo serán posibles gracias a la circunstancia del medioevo, que en palabras de Fioravanti originó: "en fin, lo que emerge de todo esto es la gran figura de la potestas temperata, de un poder que inevitablemente y cada vez más aparece rodeado de reglas y de límites" (Fioravanti, 45). El Estado moderno es un sistema complejo, si el concepto de autoridad puede cuestionarse, ponerse en tela de duda, enjuiciarse, entonces es necesario constituir procesos, mecanismos, procedimientos y fases para dar certeza de la legitimidad y la legalidad de esos cuestionamientos.

Pero el llamado régimen feudal no constituye por sí mismo un equivalente del Estado moderno, sería una imprecisión metodológica suponerlo comparativamente, puesto que sus instituciones no son equivalentes a la Edad Moderna, ambos modelos suponen una ruptura que expresa bien Fioravanti arguyendo a la soberanía popular y al parlamento (Fioravanti, 45), para él, la interacción entre la Constitución medieval y la Edad Moderna, con su consiguiente constitucionalismo, puede vislumbrarse solamente atendiendo a la inmensa complejidad que el pensamiento político y jurídico medieval representó:

“(...) una edad tan compleja en el plano constitucional que no puede ser contenida en la forma exclusiva de la monarquía moderada, en una edad tan variada y viva que produce construcciones constitucionales como las marsilianas, tan atrevidas que induce a los modernos a vislumbrar en ellas la anticipación de su democracia" (Fioravanti, 37).

La necesidad de implantar límites al soberano será la que originará un replanteamiento en el constitucionalismo moderno sobre los controles y contrapesos de los poderes (Fioravanti, 81). Lo que se perseguirá será la obtención de la constitución "como límite y garantía" (Fioravanti, 84). García de Enterría al analizar el significado de la constitución indica sobre un riesgo: “(...) volatilizar los temas capitales de la organización política, y por de pronto, los de la legitimidad del poder, su titularidad, su ejercicio y sus límites" (García de Enterría 2001, 43). Es en este contexto que en el constitucionalismo moderno se pretenderá conciliar la idea de la soberanía con la limitación de los poderes del soberano. Pero, principalmente, porque esta limitación provendría de oponer al poder público una norma fundamental, con la consiguiente oposición de los derechos de los individuos (Fioravanti, 86). 


\section{Luis Gerardo Rodríguez Lozano y Talia Garza Hernández}

La idea de los límites será sustancial para la formación del Estado moderno y de sus experiencias constitucionales, el proyecto es la búsqueda de una forma de gobierno moderada, de un equilibrio (Fioravanti, 98). Pero a diferencia del ordenamiento jurídico medieval en el que los límites del poder guardaban otro equilibrio basado en el pluralismo y en la tradición encarnados por la constitución mixta. Por ello, García de Enterría, con justa razón, menciona que la Constitución es una idea que desciende de "los siglos medievales" (García de Enterría 2001, 44). Si la Constitución moderna se quiere plantear como un rechazo al pasado medieval ha sido utilizando un ejemplo literal, ese pasado, el que ha conformado los cimientos y los fundamentos del concepto moderno de Estado y de su Constitución, pero obviamente con las notas de su tiempo, así pues el Estado moderno con sus ideas de pactos y de individualización del derecho manifestará una concepción distinta frente a la autoridad política a diferencia de sus antecesores:

"El ensayo de Diderot muestra muy bien cómo el constitucionalismo que hasta aquí hemos conocido no solo produce limitaciones a los poderes públicos constituidos, sino que también opera en sentido profundamente inhibitorio en relación con el posible surgimiento de la gran idea del pueblo soberano, dentro de la cual simplemente se representaba la ruptura unilateral del contrato por parte de uno de los sujetos contratantes, por parte del mismo pueblo" (Fioravanti, 100).

Es notorio que el poder político en esta nueva experiencia constitucional, que se reflejará en sus dos grandes derivaciones que son el modelo francés y el modelo estadounidense, descansa sobre la idea de los límites para lo cual se estatuyen sendos mecanismos de control del poder político, que remarca García de Enterría contribuyen para que "(...) el poder no pueda pretender nunca ser superior a la sociedad, sino solo su instrumento" (García de Enterría 2001, 45). Se sigue observando aquí esta idea manifiesta de preservar al Estado desde el punto de vista a favor de la posición del gobernante, la antinomia clara del Estado moderno; por tal razón, en Europa permanecerá todavía el uso de atribuir a la ley la protección de los derechos y la Constitución se reservará como norma política; contrariamente, en Estados Unidos preferirán la solución del control de la constitucionalidad(3).

Pareciera que los europeos se hubieran decantado por la aplicación de la solución del gobierno equilibrado con la fórmula de la separación de poderes, este principio es uno de los principales instrumentos que argumentan la nueva lógica de la distribución del poder en el Estado moderno. El ideal que transita hacia un gobierno moderado y equilibrado. En Europa ocurrirán durante el periodo de la modernidad una diversidad de circunstancias y experimentos constitucionales ${ }^{(4)}$. Solo que la solución constitucional adoptada por el modelo estadounidense incorpora la práctica del control de la constitucionalidad para la obtención de un sistema equilibrado en el poder político.

A pesar de ello, el Estado moderno atravesará por una serie de transfiguraciones que son las que identifican cada momento histórico y los cambios en la sociedad civil. Pero reconocer que la transformación del Estado moderno no puede ser comprendida sin observar a su precedente en el régimen feudal, dado que el propio Estado moderno surge con las primeras monarquías absolutas, y en

(3) Véase Maurizio Fioravanti, Constitución: De la antigüedad a nuestros días. Traducido por Manuel Martínez Neira (Madrid: Trotta), 129. "Sin embargo, en la otra orilla del Atlántico, en los Estados Unidos, la práctica del control de constitucionalidad era ya bien visible".

(4) Véase Spyridon Flogaitis, The evolution of law and the State in Europe. Seven lessons (Oxford: Hart Publishing, 2014$), 36$. "Nineteenth, century Europe was, in effect a laboratory of new 'rational', 'modern' institutions and structures. Strangely for continental Europe, the political theories and practices which changed the concept and function of state did not come from the continent but from England, a country which, as we have seen in previous discussion- did not develop a comprehensive theory of state". 


\author{
Introducción acerca de las implicaciones del Estado de derecho en su relación \\ con el concepto de responsabilidad patrimonial \\ Introduction about the implications of the Rule of Law in its relation to the \\ concept of asset liability
}

este contexto histórico será que lenta pero inexorablemente se comenzarían a ceder espacios ante la oposición que representan los derechos del individuo. El Estado moderno presupone una batalla por la limitación del poder absoluto. La búsqueda de la limitación del poder del soberano se verá reflejada en la conquista que constituye el Estado de Derecho que abordaremos más adelante. Pues el Estado de Derecho con su primer elemento de legalidad comprende reglas y procedimientos que evolucionarán hasta convertirse no solamente en la configuración de controles y contrapesos del poder político, sino en un auténtico derecho que hace justiciable a la administración.

Por un lado, en Inglaterra y en otros países de Europa continental como Francia, seguirá teniendo connotada presencia el dogma de la soberanía parlamentaria ${ }^{(5)}$, Europa continental continuará muy centrada en las Constituciones estatales, contrariamente, en Estados Unidos será recibido el argumento de la soberanía popular, pero este será asimismo limitado por el principio de la supremacía constitucional ${ }^{(6)}$. Por ello, son acertadas las palabras de Fioravanti cuando afirma: "Si ahora miramos la experiencia constitucional americana en su conjunto, nos damos cuenta de que está sustancialmente dirigida a conciliar la tradición del constitucionalismo con la novedad de la soberanía parlamentaria" (Fioravanti, 109). Cada Estado tiene sus propios métodos para poder encontrar la fórmula, no solo que le dé estabilidad política al sistema, sino que pudiera alcanzar ese ideal del gobierno moderado y equilibrado.

Tarea difícil, si se toma en cuenta que el concepto de Constitución será el que distinguirá cada constitucionalismo en ambos lados del Atlántico, mientras los estadounidenses pretendieron encontrar el equilibrio deseado por un medio que es "la supremacía de la Constitución como garantía de poderes limitados" (Fioravanti, 110). García de Enterría ilustra concienzudamente esta circunstancia: "la técnica de atribuir a la Constitución el valor normativo superior, inmune a las Leyes ordinarias y más bien determinante de la validez de estas, valor superior judicialmente tutelado, es la más importante creación con el sistema federal, del constitucionalismo norteamericano y su gran innovación frente a la tradición inglesa de que surgió" (García de Enterría 2001, 51). El concepto normativo de Constitución como norma jurídica será inevitablemente una de las técnicas necesarias para la transformación del Estado de Derecho en Estado Constitucional.

La fórmula del Estado Constitucional tan recurrida en la segunda mitad del siglo $X X$, corresponde a un cambio que Zagreblesky define como transformación de "los postulados del Estado de derecho legislativo" (Zagrebelsky 2011, 33). Peter Häberle recapitula que los elementos ideales y reales del Estado Constitucional constituyen una conquista cultural, consiente que el nivel cultural alcanzado es preciso que sea conservado (Häberle 2003, 2). En su brillante artículo El Estado constitucional europeo, Peter Häberle describe al Estado Constitucional como un proyecto inacabado, una construcción histórica que se elaboró por influencias recíprocas de Europa y de los Estados Unidos. Los antecedentes de la cultura jurídica europea

(5) Véase Eduardo García de Enterría, La constitución como norma y el tribunal constitucional. 3a ed. (Madrid: Civitas, 2001), 51. "La historia inglesa, cien años antes que la continental, había hecho del Parlamento el órgano tutelar de los derechos contra el absolutismo regio, mientras que los Parlamentos continentales postrevolucionarios seguían más bien la vía de concentrar en sí mismos la suma potestad política bajo forma legislativa. La originaria concepción inglesa de la ley como "producto de justicia", más que voluntad política soberana, puede sorprender a quien tiene las ideas modeladas sobre la tradición constitucional de la Europa continental, pero a la luz de los avatares históricos del constitucionalismo inglés no tiene nada de incomprensible".

(6) Véase Eduardo García de Enterría, La constitución como norma y el tribunal constitucional. 3a ed. (Madrid: Civitas, 2001), 51. "La idea de un Derecho fundamental o más alto (higher law) era claramente tributara de la concepción del Derecho natural como superior al Derecho positivo e inderogable por este y va a ser reafirmada por los colonos americanos en su lucha contra la Corona inglesa, a la que reprochan desconocer su derechos personales y colectivos". 


\section{Luis Gerardo Rodríguez Lozano y Talia Garza Hernández}

de los que da cuenta Peter Häberle han sido constantemente abordados por los iuspublicistas y pensadores políticos y tales aportaciones las discutiremos en el ulterior desarrollo de este artículo ${ }^{(7)}$. Los estadounidenses adoptarán por medio de la judicial review un mecanismo para instrumentalizar a la Constitución como un medio de control de la constitucionalidad (García de Enterría 2001, 51).

El desarrollo de la revisión judicial en Europa producirá sustanciales transformaciones en las tradiciones jurídicas de ese continente, de ese modo podemos observar como el derecho a la par de la transfiguración del Estado produce cambios, pues en Europa, describe García de Enterría, se presentará el cambio por medio de la recepción de la justicia constitucional aproximadamente durante la posguerra de 1919 (García de Enterría 2001, 56). Este cambio actualiza una característica esencial del Estado de Derecho, la ley del Estado soberano es disciplinada por reglas constitucionales que protegen los derechos de los individuos (Fioravanti, 141). La justicia constitucional es una innovación compleja que fue fuertemente propiciada por los estadounidenses quienes optaron, como señala Fioravanti, por medio del principio de la supremacía de la Constitución para instrumentar el control difuso de la constitucionalidad como un mecanismo de protección de los derechos de los individuos, pero también se encuentra otra razón, la supremacía constitucional es un mecanismo que sirve para reiterar que los poderes del Estado lo que ejercen, finalmente es, solo un poder derivado, de ello se originará la novedad de la soberanía de la Constitución (Fioravanti, 109).

No se trata de polemizar sobre ello, sino solo de encarar ese fenómeno que propiciará el reconocimiento del valor normativo de la Constitución derivado por la propia interpretación de ella, que se da sustancialmente, por medio de órganos judiciales, al inicio, previo a la innovación de la jurisdicción constitucional del modelo kelseniano de control constitucional concentrado (García de Enterría 2001, 56), que constituye una innovación del Derecho Público europeo. $Y$ todo ello propiciado por el hecho de que la ley no será únicamente la fuente de donde dimanan los instrumentos de protección de los derechos de los individuos, la Constitución es una fuente para garantizar los derechos, pero para ello será preciso interpretarlos, y eso fue lo que innovaron los estadounidenses por medio de la práctica de la judicial review.

Por consiguiente, el concepto normativo de Constitución enfatiza en la interpretación y argumentación jurídica de los derechos, por lo que para Zagrebelsky:

"(...) ya no puede pensarse en la Constitución como centro del que todo derivaba por irradiación a través de la soberanía del Estado en que se apoyaba, sino como centro sobre el que todo debe converger; es decir, más bien como centro a alcanzar que como centro del que partir" (Zagrebelsky 2011, 14).

El Estado de Derecho tiene entre sus principales aportaciones la institucionalización del principio de legalidad, con la consecuencia de subordinar la administración a la ley. Conformándose un primer avance para la colocación de límites del soberano, que en algunos casos era representado por el rey. En los Estados Unidos de América, la evolución fue distinta, como se ha mencionado, ese país escogió una forma de gobierno presidencial y la tutela de los derechos de los individuos encontró en la vía de la práctica del control difuso de la constitucionalidad y de la jurisprudencia un canal apropiado. En Europa, el sistema de control constitucional fue diseñado como una "función constitucional que no sería propiamente judicial" (García de Enterría 2001, 57). La elección de este sistema en Europa del que Kelsen fue uno de los principales articuladores obedece a profundas razones históricas, que tienen como como núcleo una tradicional desconfianza a los jueces:

(7) Véase Peter Häberle, El Estado constitucional. 2a ed. Traducido por Héctor Fix-Fierro (México: Universidad Nacional Autónoma de México, 2003), 2. "La teoría constitucional europea debe subrayar que cada nación ha prestado, a largo plazo su específica aportación a esta obra colectiva” (Häberle 2003, 2). 
Introducción acerca de las implicaciones del Estado de derecho en su relación con el concepto de responsabilidad patrimonial Introduction about the implications of the Rule of Law in its relation to the concept of asset liability

"(...) en el momento en que Kelsen construye su sistema, tienen en toda Europa y, especialmente en el mundo germánico, las posiciones románticas y vitalistas de 'Escuela libre del Derecho', 'libre jurisprudencia', 'comunidad del pueblo' (Volksgemeinshchaft), etcétera, que alimentaban una revuelta de los jueces contra la Ley y que tan fácilmente, además, podría apoyarse en la formulación abstracta y general de ciertos principios constitucionales. Prohibiendo a los jueces que inapliquen las Leyes, el sistema pretende reforzar los mecanismos de sumisión de la jurisdicción a la legislación y de primacía parlamentaria en un momento en que los jueces tienden a valorar negativamente el acceso a las Cámaras de nuevas fuerzas tradicionales y políticas capaces de trastocar los valores tradicionales" (García de Enterría 2001, 58).

Paradójicamente, la tradición europea reforzará el derecho público y, consiguientemente, hará justiciable a la administración. Lo cual es producto de la maduración del Estado de Derecho. Porque ese fuerte reforzamiento de las constituciones estatales es lo que permitirá limitar a las administraciones. El Estado aumentará demasiado su intervención, por lo tanto será urgente generar contrapesos, es lo que dará como resultado un capítulo interesante en la administración de justicia: la jurisdicción contenciosa administrativa como defensora de los intereses de los particulares frente a los excesos y arbitrariedades de la administración.

Para transitar de un concepto de Estado centrado en la posición privilegiada de los gobernantes y de sus prerrogativas, a un concepto de Estado de Derecho, en el cual los propios gobernantes y la administración deben someterse a la ley, como los individuos, aunque cada uno en sus respectivos órdenes jurídicos, fue necesario establecer normas y mecanismos en el derecho público que contemplaran esas situaciones, esta transformación es expresada por Castro Estrada con las siguientes palabras:

"No podría denominarse Estado de Derecho, a aquel que en forma expresa o tácita no admitiera sus responsabilidades jurídicas derivadas de la relación que mantuviese con sus administrados. Tal régimen de excepción, de inmunidad e impunidad sería la antítesis de un Estado de Derecho merecedor de dicha connotación" (Castro 2006, 8).

En su momento, se abordará todo lo conducente al Estado de Derecho; sin embargo, es apropiado puntualizar en este sentido, que el principio de legalidad es sustancial para la institucionalización de un sistema de responsabilidad. No basta solamente la responsabilidad política, cuyos orígenes encontramos en el derecho anglosajón con la responsabilidad política propia de los sistemas parlamentarios que es una muy importante innovación, pero no es la única ni el fin de los mecanismos pues tiene sus limitaciones.

El Derecho Administrativo tendrá que generar, consiguientemente, sus instituciones, como lo es la de la responsabilidad patrimonial. La responsabilidad patrimonial tiene que entenderse a partir del contexto histórico en el que aparece (Künnecke 2007, 185). Entonces, el sistema disciplinario y de responsabilidades en el Estado de Derecho surge como una instrumentación del principio de legalidad para someter las actuaciones de la administración al Derecho, pero oponiendo a ello los derechos de los particulares. Lo cual consiste en que los actos de la administración, del gobierno son justiciables. Lo ideal es que la determinación de las responsabilidades de la administración sea imputada, cuando sean conducentes, por medio de un órgano jurisdiccional, dado que no es suficiente por medio de la autotutela de la administración.

Entre los orígenes del sistema de justicia contencioso-administrativa o jurisdicción contencioso-administrativa se encuentra el modelo francés, en el que se presentó la importante evolución de la justicia retenida a la justicia delegada, la cual operará un verdadero cambio para la constitución de una jurisdicción contencioso-administrativa. Entre los motivos, como se ha mencionado, se encuentra que las administraciones en los Estados nacionales europeos se ensancharon, generándose estados muy fuertes, con elevadas burocracias. Esto motivaba que el derecho de la administración fuera un importante instrumento para la realización de 


\section{Luis Gerardo Rodríguez Lozano y Talia Garza Hernández}

las actividades de interés general, pero que el consiguiente principio de legalidad fuera progresivamente limitando a la administración. Esta podría ser fuerte, pero sus actos, los actos reglados del gobierno, tendrían que cumplir con las condiciones de legalidad, pero la legalidad en el Estado Constitucional no es el único objetivo.

El Derecho Administrativo producirá una de las instituciones que mejor reflejan las garantías del ciudadano frente a la administración pública y en esto consiste la responsabilidad patrimonial del Estado. Desde luego, esta institución constituye un régimen que se inscribe en el campo del Derecho Administrativo, pero comparte algunas identificaciones con el común de otras instituciones del derecho público y privado, solo que la responsabilidad patrimonial del Estado se ha diferenciado de la responsabilidad política y la responsabilidad civil para configurarse como una institución autónoma que se estudia y aplica a través de la metodología y los principios del Derecho Administrativo (Castro 2006, 19).

Lo más significativo de la institución de la responsabilidad patrimonial del Estado, y que será abordada con mayor detenimiento en su momento, es que este no fue únicamente un constructo del principio de legalidad en el Estado de Derecho, y en ello hacemos nuestras las palabras de Castro Estrada:

"(...) dentro de esa unidad que constituye el propio ordenamiento jurídico, coexisten una serie de fuentes del Derecho que surgen de la realidad histórica y que tienen como aspiración o pretensión última la realización de la justicia, aunque también participan igualmente otros valores como el orden, la paz, la seguridad y el bien común" (Castro 2006, 15). Determina Castro Estrada que de los valores se infieren aquellas fuentes no positivadas en el Derecho, entendiendo por ella los principios generales del derecho (Castro 2006, 8). Lo concreto es que la legalidad no es la única condición para la realización de los valores en el orden social concreto, aunque una referencia no disciplinada de los valores podría generar un tamiz interpretativo. Lo verdaderamente útil es el requerimiento de otro principio igualmente trascendente: el principio de responsabilidad del poder público, como bien lo hace notar Castro Estrada (Castro 2006, 19).

La responsabilidad patrimonial del Estado es una institución esencial para el Estado de Derecho, pero su total aceptación no estará exenta de ciertas resistencias que obedecen a factores políticos, por ello es sustancial que antes de pasar al estudio de la institución de la responsabilidad patrimonial del Estado, tenemos que precisar nuestro objeto de estudio, que se enfoca en esa institución, aunque reconociendo que se trata de un régimen del gran capítulo de la responsabilidad del Estado, el cual se encuentra en el campo de estudio del Derecho Administrativo.

El principio de responsabilidad del Estado es esencial para el control de la actividad administrativa. La administración pública precisa de una serie de controles, entre los que se encuentra la institución de la responsabilidad patrimonial del Estado. El Estado de Derecho es una gran maquinaria que se integra por reglas, procesos y procedimientos, que contribuyen para generar el ideal del gobierno moderado y equilibrado que fue plasmado por el pensamiento moderno. En consecuencia, todo el logro del Estado de Derecho se resume en la búsqueda de un sistema de controles, dentro de los cuales se originará una institución particular que es la responsabilidad patrimonial del Estado.

Los controles que se han mencionado pueden ser jurídicos y sociales. Frecuentemente, el Estado de Derecho, en el que predomina la importancia de lo legal, es comprensible que sean los controles jurídicos los más reforzados; por eso, precisamente, se pueden observar distintos subsistemas de controles, como lo son el control político y el control jurisdiccional. El control político es el realizado por el ejecutivo y por el poder legislativo; el control jurisdiccional es predominantemente una función jurisdiccional.

Es comprensible que en Europa continental se decidiera que prevaleciera la ley, la Constitución no había sido instrumentalizada, pero paradójicamente el desarrollo de Estados 


\author{
Introducción acerca de las implicaciones del Estado de derecho en su relación \\ con el concepto de responsabilidad patrimonial \\ Introduction about the implications of the Rule of Law in its relation to the \\ concept of asset liability
}

con poderes ejecutivos fuertes planeó que en el Derecho Administrativo tuvieran lugar innovaciones como la de la institución, objeto de nuestro análisis, que ejercían un control sobre una administración con un conjunto considerable de atribuciones. Lo que sucede es que en el continente europeo, en los sistemas parlamentarios, la separación de poderes entre gobierno y parlamento no es tan rígida como en los sistemas presidenciales.

En los sistemas presidenciales, sí se da una separación tajante entre la función gubernativa/ejecutiva y la función parlamentaria. Por eso, en un sistema estadounidense, el principio de supremacía constitucional y con la práctica del control difuso de la constitucionalidad, el sistema contaba con contrapesos aceptables. Además, de que la función de los jueces no fue vista con desconfianza, así no sucedió en Europa, donde la función jurisdiccional cargaba con resabios medievales o de desconfianza en la interpretación. En Europa continental, la figura del ejecutivo, también objeto de discrepancias, fue contrapesada oponiéndolo al Estado legislador. El Derecho Administrativo es el derecho de la administración, pero es un producto de la desconfianza, del interés de tener una administración reglada, paralelamente el Estado legislador acabaría por decaer lo cual se refleja en el desarrollo de los sistemas de justicia constitucional y de la justicia contencioso-administrativa, dos grandes capítulos del Estado Constitucional europeo, continuación del modelo del Estado de Derecho.

Consiguientemente, el ordenamiento jurídico ha requerido la introducción del instituto de responsabilidad patrimonial del Estado, entre algunas causas se encuentra aquella que alude a la búsqueda del equilibrio entre las garantías del administrado y las garantías del interés general (Blanquer 1997, 17). Esta institución, como describe Blanquer deriva en "la responsabilidad de las administraciones públicas" (Blanquer 1997, 18).

A la conformación del régimen de responsabilidad patrimonial del Estado confluyen los principios constitucionales, como el principio de la legalidad de la administración y el control jurisdiccional de la administración; los principios generales del derecho; las garantías del interés general, y las garantías del ciudadano lesionado (Blanquer 1997, 20). Por supuesto que este régimen es una especie del sistema de responsabilidad del Estado de los poderes públicos (Celdrán 1996, 16) aún en desarrollo, y se ha consagrado en un principio básico del Estado Constitucional. De las innovaciones que se produjeron en la transfiguración del Estado de Derecho hasta el actual modelo ideal de Estado Constitucional, se destaca el principio de responsabilidad ${ }^{(8)}$.

$Y$ es en el Derecho Administrativo en el cual el régimen a estudiar, el de responsabilidad patrimonial, se ha consagrado por medio de la teoría de la responsabilidad patrimonial, pero constituye un logro significativo, dado que es una especie en el gran sistema de la responsabilidad estatal, que en su particularización administrativa garantiza que el administrado pueda ser resarcido por lesiones causadas por las autoridades administrativas. Pero la responsabilidad patrimonial del Estado ha evolucionado en distintas vertientes como la social, la solidaridad, la ambiental y la reparación, no únicamente centradas en el carácter patrimonial de la responsabilidad.

Pero nos interesa dejar bien asentado, que aun cuando la institución de la responsabilidad patrimonial del Estado pertenece a las instituciones propias de la disciplina del Derecho Administrativo, no deben dejar de analizarse teniendo como referencia la generalidad a la que se adscriben y que consiste en que forman parte del conjunto del sistema de responsabilidad estatal y este signo es lo que les confiere su nota distintiva frente a otras instituciones de control y la razón argumentativa que ha permitido que la doctrina haya podido determinar la pertinencia de esta institución.

(8) Véase Peter Häberle, El Estado constitucional. 2a ed. Traducido por Héctor Fix-Fierro (México: Universidad Nacional Autónoma de México, 2003), 7 en el que destaca que el Estado Constitucional puede normar deseos de utopía concretos como el principio de responsabilidad. 


\section{Luis Gerardo Rodríguez Lozano y Talia Garza Hernández}

Por ello, precisamos de vincular a la responsabilidad patrimonial con el Estado, este que es su fuente, una institución que resulta de un proceso evolutivo en el que el objetivo capital ha sido limitar al poder político, debilitar las tentaciones del absolutismo, pues cuando el poder político se manifiesta limitado, cuando un órgano del estado concentra mayor poder, las garantías del ciudadano languidecen. $Y$ esta evolución se desplegará por medio de las transfiguraciones del Estado y suponen, como se ha insistido, una trascendente evolución del propio derecho y de sus instituciones (Castro 2006, 21).

El Estado de Derecho contiene todo un conjunto de instituciones, algunas serán de derecho privado, otras de derecho público, pero a todas les corresponde una determinada función, cernida en su operación a los principios jurídicos. Pero se ha insistido en que el Estado legal no es suficiente, por ello la importancia de la función de la garantía en el Estado Constitucional. Y en esto la responsabilidad patrimonial como institución del Derecho Administrativo se determina como una garantía de los administrados. Nuevamente, la noción de garantía no es exclusiva del derecho público, también aparece en el derecho privado, pero obviamente en el derecho público tiene una significación más amplia referida a los derechos fundamentales.

La institución de la responsabilidad patrimonial del Estado es indisociable de los derechos fundamentales. No es casual que su reforzamiento teórico haya tenido lugar en el estadio histórico del estado correspondiente al Estado social, a medida que evolucionan los derechos, también tienen que evolucionar los medios para garantizarlos. Actualmente, la responsabilidad patrimonial del Estado es una institución, que tiene la obligación de adaptarse a los cambios que ocurren en la sociedad, en el Derecho Administrativo y por lo tanto en el Estado.

El Derecho Administrativo en este caso no ha sido ajeno a la transformación que se ha originado en el derecho en general y que tiene relación con los principios y valores, la globalización y los derechos humanos, acerca de ello José Luis Meilán Gil formula con claridad este proceso:

"Las declaraciones y convenciones de Derechos Humanos han mostrado su virtualidad expansiva de varias maneras.
Sin ánimo de jerarquizar por criterios de importancia, una de ellas es su configuración como derechos fundamentales de los Estados, que han de ser interpretados conforme a esas declaraciones, evitando, como se acordó en Helsinki en los comienzos de los años setenta, que el reconocimiento de los mismos fuese interpretado unilateralmente, lo que equivalía a desvirtuarlos, aunque subsistiesen formalmente" (Meilán 2011, 43).

La expansión de los derechos ha generado mayor labor para los Estados y aunque estos quisieran interpretar a su favor el principio de progresividad de los Derechos Humanos, el ulterior principio de no regresividad de Ios Derechos Humanos es bastante útil para proteger lo logrado; para avanzar en la protección y garantía de los Derechos Humanos, en el enfoque transversal de los derechos, como a algunos gobiernos les gusta llamarle, si se tiene la amenaza del déficit presupuestario y de la deuda pública. $Y$ en esto reside la preponderancia del sistema de responsabilidad del Estado y su derivación en responsabilidad patrimonial. Las limitaciones que generalmente tienen que sufrir la población en su garantía de derechos por una falta de control y de sanción de los actos indebidos y dolosos de la administración que causan perjuicio al patrimonio público, a los bienes públicos. Asunto nada sencillo. Por ello, la institución de la responsabilidad del Estado debe ser analizada en el contexto y con la metodología del Derecho Administrativo, pero sin ser indiferentes hacia la estructura del Estado que se encuentra, dado el proceso de globalización, ya gestada en una inminente transformación política y social que tiene lugar en los terrenos del derecho, de la justicia y hasta de la burocracia como ha

(9) Véase Sabino Cassese, Los tribunales ante la construcción de un sistema jurídico global (Sevilla: Derecho Global, 2010$), 18$. "Así las cosas, el Derecho está ocupando, aunque muy lentamente, el lugar de la política en el panorama global. Si en un primer momento el protagonismo de la resolución de los conflictos internacionales pasó de los soldados a los embajadores, 
Introducción acerca de las implicaciones del Estado de derecho en su relación con el concepto de responsabilidad patrimonial Introduction about the implications of the Rule of Law in its relation to the concept of asset liability

observado Cassese( ${ }^{(9)}$. De este modo, sí es de suponer que este proceso de globalización ha presentado sus ventajas y desventajas, ha tenido ganadores y perdedores. El derecho con sus instituciones, con sus técnicas deberá contribuir para atemperar las desigualdades y poder procurar el equilibrio ideal para los gobiernos.

Entonces, no es adecuado pretender analizar la institución de la responsabilidad patrimonial del Estado empleando anacrónicas categorías diseñadas en el marco del Estado-Nación, porque la realidad social ha comprobado que la soberanía nacional se ha erosionado. Esto por supuesto ocurre en el Derecho Administrativo, que se ha actualizado para adaptar sus instituciones y sus categorías teóricas ante los desafíos que la globalización presenta. Por ello, en el Derecho Administrativo, los Derechos Humanos y las garantías, la cuestión ambiental y la responsabilidad patrimonial del Estado ajustada a las nuevas circunstancias han adquirido un papel protagónico que ha debido de ser analizado y estudiado por los iuspublicistas.

El Derecho Administrativo y el Derecho Constitucional son dos disciplinas que siguen teniendo una vigencia para la interpretación de los fenómenos y problemas que la globalización engendra y que muchos de ellos serán solucionados por las técnicas que ofrece el derecho. Obviamente, la inclusión de las minorías, la creciente participación política de las poblaciones han generado muchos cuestionamientos a la forma tradicional en la que el Estado-Nación se venía organizando. El equilibrio logrado por el modelo de Estado nacional que resulta de la Francia revolucionaria contribuyó para la vigencia de los principios constitucionales, el modelo de Estado de Derecho, las garantías de los derechos de los ciudadanos, en sí se pretendía devolver un equilibrio al modelo del régimen feudal que entró en decadencia en Europa y que, como explicaremos a continuación, atravesó por distintas etapas de formación en Europa y posteriormente en Estados Unidos que le confirieron ese carácter constitucional.

Solo que ahora en el siglo XXI, el modelo de Estado-Nación se sigue modificando y con ello este sistema de equilibrios y de contrapesos que se heredaron con el modelo que impulsó la revolución francesa. Las migraciones y los conflictos armados, la crisis de los partidos políticos en sociedades como la mexicana son una clara muestra de que el centro de gravedad del poder político se está transformando. El Derecho sigue desempeñando un papel ante esta realidad tangible que ha dado como resultado un pluralismo de ordenamientos descrito por Cassese (Cassese 2010, 19). Es ese el motivo por el que mencionábamos que la interrelación entre los derechos fundamentales y el sistema disciplinario y de responsabilidades del Estado no es retórica, dado que, siendo realistas, la garantía de los derechos tiene un costo dinerario y en la medida en que el sistema de responsabilidad estatal pueda ser eficiente, se pueden obtener costos que puedan ser percibidos por la población de forma concreta.

La armonización de esta pluralidad de ordenamientos ha traído diversas consecuencias, que Cassese menciona consistentes en "la fragmentación de los regímenes u ordenamientos jurídicos sectoriales ('regímenes globales independientes') y, de otro, la proliferación de tribunales internacionales organizados de modo heterárquico" (Cassese 2010, 20). ¿Por qué es importante mencionar la pluralidad de ordenamientos en relación al sistema de responsabilidad del Estado? Porque a medida que la globalización avanza, pareciera que las categorías tradicionales del Estado de Derecho del Estado-Nación no pudieran operar con normalidad para hacer visibles las responsabilidades de los gobernantes o de los servidores públicos y esto es utilizado retóricamente por quienes detentan el poder político para eludir la rendición de cuentas.

Por otra parte, no se puede dejar de lado otra realidad consistente en la creciente desigualdad

ahora presenciamos un trasvase de los embajadores a los jueces. Cada vez con mayor frecuencia los tribunales están "cruzando fronteras" y éste es un fenómeno que puede observarse igualmente en términos de burocracia (lo que se ha venido en llamar "intergubernamentalismo") y desde la misma teoría jurídica". 


\section{Luis Gerardo Rodríguez Lozano y Talia Garza Hernández}

social y económica, por lo cual en la globalización se asiste a otro problema, no se concentra solamente el problema de la desigualdad entre ciudadanos y el Estado, pues no es menor la desigualdad entre el ciudadano y las corporaciones financieras y esto último también es susceptible de ser estudiado a la luz del Derecho Administrativo, Cassese sobre esto ha mencionado que "(...) algunos Estados (los débiles) no controlan, sino que son controlados por los mercados" (Cassese 2014, 18). Todo esto como quiera es comprensible desde la teoría política, pues finalmente en el Estado, como analizó en su momento Poulantzas, las relaciones capitalistas de producción originan la formación de varias clases de las cuales varias pueden desempeñarse como clases y fracciones dominantes (Poulantzas 2001, 387). El Derecho Administrativo es una de las disciplinas más apropiadas para entender la constante preocupación de los administrados por limitar la dominación política. Traduciendo su esfuerzo en una relación jurídica, para la que la idea del contrato fue crucial en el nacimiento del Estado moderno.

Ciertamente, la desigualdad social no es el único desafío que tiene que interpretar el Derecho Administrativo en el contexto global, el papel de los organismos financieros trasnacionales tiene que ser analizado con otras categorías que exceden los objetivos de esta investigación y cuya complejidad trasciende a nuestra investigación y su abordaje distorsionaría el hilo metodológico de este artículo. Pero no podemos desaprovechar este espacio para advertir que el Estado en la globalización no es el único sujeto responsable, pues existen otras corporaciones que concentran también un poder de decisión sustancial.

Ahora, en el siglo XXI los mecanismos del mercado suelen ser calificados por un sector de los medios como infalibles, el Derecho Administrativo es un recurso útil para someter al Estado todavía más a respetar los derechos y garantías del ciudadano, recordándole a la administración que esta no es infalible. Esta idea se aproxima más a la idea del constitucionalismo democrático.

Además de la desigualdad ya planteada, la globalización no solo nos ha demostrado la erosión del Estado, apropiadamente, Habermas expuso en Más allá del Estado Nacional, una tesis aun actual:

"(...) las diversas tendencias a la globalización del tráfico, de los contactos y de las comunicaciones, de la producción económica y de su financiamiento, de las transferencias en tecnología y armamento, del comercio de drogas y de la criminalidad, y sobre todo de los peligros tanto estratégicos como ecológicos, nos confrontan con problemas que ya no pueden solucionarse dentro del marco del Estado nacional" (Habermas 199, 183).

Entre otros de los problemas que ya venían manifestándose en el marco del EstadoNación, se encuentra el problema del medio ambiente, su análisis por la ciencia del derecho le corresponde al derecho del medio ambiente, pero sigue encontrándose muy interconectado con el Derecho Administrativo, esto se debe a que la corresponsabilidad por los daños al medio ambiente no solamente pueden analizarse a la luz del derecho estatal, sino también del derecho privado y de las corporaciones trasnacionales.

El siglo $X X I$ se caracteriza por la búsqueda de un equilibrio en el orden internacional, en el cual organismos multilaterales como el sistema de Naciones Unidas ocupan un espacio estelar para el desarrollo de una política en el ámbito internacional civilizada y que las relaciones entre los Estados se resuelvan por la vía pacífica. Nadie pone en discusión la pertinencia y la vigencia de la institución de la responsabilidad del Estado, pero si son analizables y revisables sus regímenes, conforme las transformaciones que en el Derecho y el Derecho Administrativo en particular se van percibiendo.

Parafraseando a Skinner, el Estado se ha desenvuelto en diferentes circunstancias históricas que atienden a criterios culturales, geográficos, lingüísticos, etcétera y en todos ha comprobado su supervivencia, todas estas realidades son las que han determinado la identidad del Estado, pero desde una perspectiva comparativa el Estado tiene que 
Introducción acerca de las implicaciones del Estado de derecho en su relación con el concepto de responsabilidad patrimonial Introduction about the implications of the Rule of Law in its relation to the concept of asset liability

reunir ciertas condiciones para ser considerado como tal, están entonces los elementos tradicionales de población, territorio y poder, pero son las variantes particulares las que le dan a cada conformación, si se trata de un modelo nacional, su identidad, pero el Estado no es solo cultura es sobre todo un modelo de organización social, que puede ser independiente de la cultura o de una nación, es un asunto de poder político. El Estado evoluciona para adaptarse como escribimos al principio de este párrafo a las épocas históricas. En este artículo, analizaremos las principales formas que el Estado ha adoptado, a saber, el Estado Absoluto, el Estado de Derecho, el Estado de Bienestar y el Estado Neoliberal, las cuales estudiaremos para analizar como el Estado ha evolucionado a la par de que se ha ido innovando con la institución de la responsabilidad patrimonial del Estado como una técnica necesaria dentro del sistema de responsabilidad estatal, para la adopción de medidas que incluyen procedimientos y sanciones para los funcionarios que infrinjan las normas del sistema.

La etapa del Estado en la que actualmente nos encontramos es el denominado modelo de Estado Neoliberal, en la que las categorías del Derecho Administrativo todavía siguen desempeñando una función esencial para la protección y garantía de los derechos del administrado. Pero todavía es apremiante continuar en el análisis de la institución de la responsabilidad patrimonial del Estado. Su evolución depende de la medida en que se puedan eliminar las resistencias que las facciones dominantes en el Estado, obedeciendo a su propia lógica del poder, suelen oponer; para Serra Rojas, por motivos económicos o renuencia para asumir nuevas obligaciones jurídicas (Serra 1972, 1323). Pero Serra Rojas menciona que esos daños merecen reparación. Porque se trata de un tema de justicia y es que sin pretender ser redundantes deseamos afirmar que la responsabilidad patrimonial del estado es, fundamentalmente, un asunto de justicia.

$Y$ es que el tema de la justicia no es el primer elemento que se pretende en el Estado, inicialmente la justicia en el orden medieval era entendida como un asunto predominantemente jurisdiccional, pero en el Estado moderno no será así. El resultado de esta evolución en el tema de lo justo tiene entre sus principales exponentes el logro de la jurisdicción contencioso-administrativa. La justicia no solamente se impartirá por órganos formalmente jurisdiccionales, también pueden intervenir los demás órganos públicos.
La justicia no es solamente un asunto jurídico, es por lo tanto un asunto de valores, el pensamiento positivista pretendió enfatizar en la ley, como el principal instrumento para la resolución de las controversias jurídicas. Pero la legalidad no significa necesariamente justicia. Cuántas veces, por ejemplo, se puede constatar que a las administraciones les cuesta admitir sus responsabilidades. El logro del derecho público es que al reconocérsele al Estado personalidad jurídica inmediatamente este pasa a ser justiciable. Pero lo que pretende el Derecho con su generalidad es conformar un supuesto legal, en el cual su eventual incumplimiento acarrearía una sanción. Pero de no existir el incumplimiento la sanción no procedería. La maquinaria del Estado funciona entonces, a través de estímulos en los cuales, el cumplimiento o incumplimiento por parte de la administración de sus funciones determinará el resultado.

Como se sugerirá en su momento, en la institución de la responsabilidad patrimonial del Estado se pueden presentar diversos supuestos, pero el acto de la lesión implica la condición de una futura imputabilidad. De las respuestas que deriven por medio de una adecuada metodología en el derecho administrativo depende la correcta aplicación de la institución de la responsabilidad patrimonial del Estado para que sea propicia a las nuevas circunstancias y funcione como un verdadero instrumento para garantizar los actos que lesionen a los administrados o situaciones que puedan equipararse, que es lo que motiva el estudio de esta figura en el contexto actual.

Sin duda, que la vinculación del Derecho Administrativo a la Constitución, a los principios constitucionales del Derecho Administrativo, a no desconocer la influencia de los principios generales del Derecho ha generado este sistema de justicia administrativa que es del que se desprenderá el sistema de responsabilidad 


\section{Luis Gerardo Rodríguez Lozano y Talia Garza Hernández}

del Estado. Obviamente, este sistema tiene una estructura ideológica que se manifiesta en la corriente jurídica del neoconstitucionalismo, que con sus doctrinas ha generado una nueva visión de la Constitución, en la que esta es una norma jurídica. Todo esto ha motivado las transformaciones que el Derecho Administrativo ha debido encarar, puesto que la Constitución no es solo una norma política o un sistema de reglas, sino que a su vez contiene principios y valores de los cuales uno de los principios articuladores lo es el principio de dignidad humana.

También se requiere remarcar un cambio de mentalidad y de valores para los operadores jurídicos, que Martín Jiménez describe así:

"para nosotros lo fundamental es remarcar como los valores se introducen en el derecho en virtud de la intencionalidad humana, la cual, apoyada en la conciencia del derecho, es capaz de dotar a la norma jurídica de contenidos axiológicos, lo que da lugar a la formación de los conceptos jurídicos" (Martín 2014, 308).

Los valores en las postrimerías del Estado del siglo XXI, mencionando con sumo cuidado a la noción de Estado global, hace más urgente no desconocer la influencia que desempeñan los valores como fuente en los sistemas constitucionales modernos, procuramos con estas reflexiones que el lector pueda apreciar que los alcances de la institución de la responsabilidad patrimonial del Estado tiene implicaciones en la propia génesis del Estado moderno.

\subsection{El Estado absoluto}

La formación política del Estado absoluto es producto de la pérdida de equilibrio de la forma de descentralización política de los ordenamientos medievales. El proceso de gestación del Estado feudal absolutista tendría lugar entre el siglo XIII y XV en la sociedad europea, particularmente en Francia, Inglaterra y España, y sucede como consecuencia de los fuertes problemas económicos que presentó la crisis del modelo de producción feudal. Perry Anderson, uno de los grandes estudiosos de este periodo, considera que el nacimiento del modelo de Estado absolutista durante el siglo XVI significó un rompimiento con el esquema fragmentario y jerárquico de las "formaciones sociales medievales" fuertemente cimentadas por dos instituciones que fueron los feudos y estamentos, originando que se asentaran "monarquías centralizadas" (Anderson 1990, 10).
La decadencia del modelo social medieval se volvió inevitable paradójicamente, la amplia disgregación del poder político motivaría la inestabilidad política que conformaría los intentos de las monarquías como ocurrió en Inglaterra para afianzar un modelo de poder estatal monista, entre otras de las causas la sociedad medieval con su rigidez estamentaria constituyó una sociedad en la que no tenía cabida la noción del individuo tal y como sería reconocido posteriormente en el estadio de las declaraciones de derechos, un cambio de mentalidad de la sociedad que sería lento pero fue la génesis del movimiento de la ilustración y del racionalismo.

Si en la Edad Media la autoridad se afianzaba por el elemento religioso, la crisis de este modelo es producto de un trasvase del pacto del poder temporal con el espiritual modelo que entró en crisis, dado que comenzaron a emerger en importancia el papel de las ciudades-estado como ocurrió en Italia, produciéndose un ciclo de inestabilidad política, de anarquía pero que resultaría en la progresiva concentración de prerrogativas en el monarca que tiene como soporte el novel y original papel de la burguesía, el creciente desempeño de las relaciones financieras y comerciales sobre lo que R. H. S. Crossman refirió como el ascenso de la burguesía como una clase social prevaleciente, el desarrollo del comercio y de las telecomunicaciones, todo esto demandaría durante el siglo XVI una mayor centralización del poder político (Crossman 1978, 31-32).

En este sentido, las ciudades-repúblicas de la Italia septentrional son donde tiene lugar la manifestación primigenia de este fenómeno como lo podemos apreciar en R. H. S. Crossman y Hermann Heller. Esto se traduciría, como era de esperarse, con las monarquías absolutas de Francia y de España y en Inglaterra por el régimen de los Tudor señala R. H. S. Crossman (Crossman 1978, 31-32). 


\author{
Introducción acerca de las implicaciones del Estado de derecho en su relación \\ con el concepto de responsabilidad patrimonial \\ Introduction about the implications of the Rule of Law in its relation to the \\ concept of asset liability
}

En la etapa del Estado absoluto, el papel del comercio y de las finanzas constituyen un aspecto esencial para entender su éxito, de manera que son las causas económicas las que permitirán la asunción de las primeras manifestaciones de un poder estatal de tipo monista, esta es una de las principales características para entender y distinguir el proceso de cambio del sistema político económico-feudal al sistema político del Estado absolutista, es decir, el creciente papel de los factores económicos ya mencionados, y que ha sido estudiado ampliamente por distintos pensadores como lo fueron Karl Marx y Friedrich Engels, quienes describieron de forma oportuna cómo es que se manifestó esta modificación de las relaciones de producción cuando cambian las condiciones de desarrollo en una sociedad:

"El modo de producción de la vida material condiciona el proceso de la vida social, política y espiritual en general. No es la conciencia del hombre la que determina su ser, sino, por el contrario, es su ser social el que determina su conciencia. Al llegar a una determinada fase de desarrollo, las fuerzas productivas materiales de la sociedad chocan con las relaciones de producción existentes, o, lo que no es más que la expresión jurídica de esto, con las relaciones de propiedad dentro de las cuales se han desenvuelto hasta allí. De formas de desarrollo de las fuerzas productivas, estas relaciones se convierten en trabas suyas. Y se abre así una época de revolución social. Al cambiar la base económica se conmociona, más o menos rápidamente, toda la inmensa superestructura erigida sobre ella" (Marx y Frederich 2009, 47).

El pensamiento político que durante la etapa del Estado absoluto será el causante de una revolución que causará un cambio radical en la mentalidad occidental. Tiene entre sus exponentes principales el pensamiento de Maquiavelo quien nos ilustra para entender el nacimiento y devenir del Estado absolutista, ya que este se da cuenta que ahí donde impera la anarquía, se antojaba sumamente difícil el progreso social. Al observar esas condiciones de inestabilidad política que solo causaban guerra y destrucción es que Maquiavelo propone con claridad un gobierno fuerte como condición necesaria para el progreso de los Estados, lo cual, en ese momento solo resultaba posible con un gobierno fuerte en todo sentido. Una de las aportaciones principales de su teorización consiste en la afirmación de la necesidad de una centralización del poder político.

La disolución del modelo feudal sería una realidad que tendría que enfrentar el continente europeo para dar lugar al nacimiento del Estado en el sentido moderno, esta crisis fue la que desencadenó la transfiguración del régimen feudal por un Estado absolutista, este nuevo modelo de Estado, el origen del Estado moderno, será el que cimentará las instituciones para el auge del liberalismo económico. Las instituciones económicas necesitaban una certeza impersonal y abstracta que no se satisfacían con el personalismo y la autoridad de las instituciones feudales. No es casual que el absolutismo sea piedra de toque para el posterior Estado liberal. En síntesis, el absolutismo, como su denominación lo indica, implicará centralización, absolutización del poder político, concentración del poder y de sus prerrogativas en la soberanía del monarca. Pero no corresponde con un modelo carismático, puesto que este proceso originará la propia institucionalización de las facultades ejecutivas del monarca y el orden mercantil como el articulador del sistema social que regía la forma política del Estado absoluto.

El pensamiento de Maquiavelo contribuyó de forma magistral para la fundamentación de la legitimidad del modelo de Estado absoluto, pues según el análisis de François Châtelet, las ideas de Maquiavelo sobre la idea del Estado son realmente modernas, ya que al intentar justificar la legitimidad del Estado en su propia fuerza, Maquiavelo contribuyó para admitir que la acción política precede a la legitimidad, lo cual es un rasgo "decisivo" de la soberanía (Châtelet 1980, 251).

Ya que aun cuando el Estado absoluto pudiese haber contenido elementos negativos en materia de distribución del capital, de la organización del trabajo y de las libertades, dado que existía una contradicción y una desigualdad entre las distintas clases sociales que integraban la sociedad, este modelo daría las garantías para que el sistema de acumulación del capital continuará desarrollándose, la modernidad de los 


\section{Luis Gerardo Rodríguez Lozano y Talia Garza Hernández}

planteamientos de Maquiavelo como lo comentábamos en el párrafo precedente se refleja en que la discusión de la soberanía se discutirá en relación a procesos formales, la legitimidad tendrá que originarse en procesos institucionales.

Pero el absolutismo solo constituirá un primer paso en la evolución hacia un orden social más justo y participativo que superará las injusticias y los excesos de la opresión que caracterizaría los elementos negativos del régimen feudal. El régimen absoluto se traducirá inmediatamente en una concentración de atribuciones ilimitadas en el poder del monarca, es en esa característica en la que Fernández Ruíz observa que se corona la transición del régimen feudal al régimen absoluto:

"En este proceso de transformación, al mediar el siglo $X V$, prolifera la sustitución del Estado feudal por el Estado absolutista, definido como aquel en que todos los poderes se hayan reunidos sin limitaciones en el monarca, conforme a un esquema económico vinculado totalmente al mercantilismo, cuyas ideas imperaron durante tres siglos, de mediados del XV a mediados del XVIII; por ello, esta versión absolutista del Estado se basa, en lo político, en la monarquía absoluta, en lo económico, se sustenta en el mercantilismo" (Fernández 2006, 23).

Las crisis de los siglos feudales XIV y XV serían en las que se produciría la lenta transición del régimen feudal al régimen del modelo de Estado absoluto, produciendo cambios que ocasionados por la pérdida de poder por parte de la nobleza feudal, el poder se fue transfiriendo hacia el monarca, se produjo el origen de los Estados-Nación, esta concentración del poder político fue originada por la propia crisis de las estructuras económicas feudales, que según lo indica Perry Anderson dio lugar a la cohesión social por medio de una monarquía centralizada bajo la cual continuarían su presencia las unidades de producción feudal pero ya evolucionadas, puesto que el crecimiento del mercado aunado a un rompimiento del tradicional esquema en el cual la explotación económica de estas unidades feudales aparejaba un esquema de derechos que se perpetuaba, esto desapareció. Ahora el eslabón que concentraba todos estos cambios se legitimaba y proyectaba en la monarquía ya no feudal, los monarcas no eran una corporación más en la disgregación del poder político, sino que se encontraron en la "cúspide" de ese sistema social.
Así las cosas ocurrieron una renovación del sistema de propiedad, de los derechos adquiridos sobre la propiedad en el que a la vez que los antiguos integrantes de los estamentos iban obteniendo derechos progresivos, el monarca concentraba mayor poder político (Anderson 1990, 14). Entonces paradójicamente aun cuando la nobleza feudal iba perdiendo gradualmente el control de la organización y distribución de la tierra, el monarca beneficiario de esa reorganización de las relaciones sociales concentraba el poder de manera absoluta.

En el Estado absoluto, la relación que se establecía entre el monarca y el individuo era de subordinación. La característica del Derecho Administrativo como Derecho que norma y reglamenta la actuación de la administración pública era desconocida y ajena de acuerdo a como funcionan nuestras instituciones en la actualidad, herederas del cambio de paradigma del movimiento de la Revolución Francesa de 1789. Si bien comienzan de forma gradual a establecerse los cimientos de la burocracia y la técnica de la administración, el Derecho se interpretaba desde el punto de vista favorable al poder político, no al de los particulares. El término garantía de los anglosajones se origina desde los tiempos medievales y tiene que ver con una protección, un pacto al que se podían amparar pero como una concesión del monarca. La visión de la garantía como un sistema de protección de reparación, autónomo al que el monarca está obligado en virtud de un contrato social, no sería una interpretación inmediatamente acogida por el derecho administrativo de la época. Si bien el término garantía continuaría abriéndose paso, desde la perspectiva de cómo se iban asegurando los derechos del individuo. La visión del Estado absoluto se fundamentaba en la posición privilegiada del gobernante.

Este modelo de Estado es pues un modelo previo al Estado liberal, en el que el Estado 
Introducción acerca de las implicaciones del Estado de derecho en su relación con el concepto de responsabilidad patrimonial Introduction about the implications of the Rule of Law in its relation to the concept of asset liability

interviene en forma mínima, su principal función consiste en proporcionar seguridad para sus habitantes y resolución de sus controversias, la seguridad y defensa exterior, tenemos Estados-naciones enfrentados, tienen que destinar dinero a las milicias y proteger sus fronteras de los ataques, evitar la pérdida del territorio. Con esta forma de Estado, no se constituye un sistema disciplinario y de responsabilidades. Así las cosas, según Luis H. Delgadillo, la Administración del Estado reúne las siguientes características: (i) soberanía del monarca, su posición es de supremacía sobre instituciones y personas; (ii) ausencia del concepto de responsabilidad política y patrimonial del monarca; y, (iii) el monarca no podía ser enjuiciado por sus actos (Delgadillo 2010, 24).

Atendiendo a los razonamientos del jurista Diego Valadés, el modelo de Estado absoluto consistió en lo siguiente:

"Concentración del poder en el monarca; la legitimidad del poder se originaba por la sucesión hereditaria, el linaje y la determinación divina (nota religiosa); centralización de las potestades; ausencia de un sistema de controles y de responsabilidad; dominio; concentración de facultades como reclutamiento militar, facultades impositivas, resolución de controversias jurisdiccionales y concentración de la autoridad política y militar en un solo órgano y la gestación de una relación de sumisión ante el poder político" (Valadés 2010, 288).

Aun cuando tuvo sus aciertos este sistema, no sería el idóneo para la constitución de un sistema disciplinario y de responsabilidades. Las instituciones del Estado absoluto no permitían el desarrollo de un Derecho Administrativo que contuviera este sistema. Pues el sistema disciplinario y de responsabilidades depende para su existencia de que los sujetos sean sujetos a derechos y obligaciones regulados por el Estado. El Derecho Administrativo es un derecho que en su evolución pretende normar y limitar a la administración, por lo que el Estado absoluto impedía cualquier medio de responsabilidad de los gobernantes y de la administración de rendición de cuentas frente a los particulares.

\subsection{El Estado de Derecho}

El régimen feudal y el absolutismo, cada uno con sus instituciones, ejercieron opresión sobre los individuos que desencadenaron que sus instituciones fueran decayendo y que las clases sociales decidieran participar activamente de los cambios sociales, aprovechando las circunstancias de cada época. Los individuos cada vez con mayores demandas de protección de sus derechos individuales fueron presionando al Estado absoluto lo que produjo el advenimiento del modelo de Estado de Derecho. Clase de Estado que se caracteriza por la oposición del individuo frente al Estado, el derecho individual del individuo como un conjunto de prerrogativas que le protejan frente a las arbitrariedades del poder público. El instrumento para poner en marcha este mecanismo es la ley. El Estado está sujeto al Derecho. El soberano tiene que admitir que los sujetos que integran el Estado tienen derechos frente a las primigenias administraciones, se origina una relación bilateral entre el Estado y los individuos que se fundamenta en una norma abstracta e impersonal que es la ley, en el principio de la legalidad. Son los instrumentos formales del nuevo modelo de Estado que exige conforme a la época acciones con arreglo a procedimientos racionales, impersonales y abstractos. En el Estado de Derecho sigue existiendo un control, no tiene cabida la anarquía solo que los métodos de control social se ejercen sobre los individuos de manera consensuada por una relación abstracta e impersonal que se representa por la ley, por las normas jurídicas, abarcando diferentes tipos de mecanismos del que su máxima expresión será llegado su momento: la Constitución, a través de un conjunto:

"Los mecanismos constitucionales que caracterizan al Estado de Derecho tienen el propósito de defender al individuo de los abusos de poder. Dicho de otro modo, son garantías de libertad, de la llamada libertad negativa, entendida como la esfera de acción en la que el individuo no está constreñido por quien detenta el poder coactivo a hacer lo que no quiere y a la vez no es obstaculizado para hacer lo que quiere" (Bobbio 2002, 21). 


\section{Luis Gerardo Rodríguez Lozano y Talia Garza Hernández}

\begin{abstract}
El Estado de Derecho se germinará por medio de los diferentes movimientos revolucionarios que tuvieron lugar en el siglo XVII en Inglaterra y en el siglo XVIII en Francia, estos movimientos indudablemente forjaron una nueva clase de Estado, solo que continuaba en su derivación de Estado Liberal, aunque en el marco ya descrito del Estado de Derecho. En el Estado Liberal que fue famoso por la fórmula del liberalismo económico: laisser faire et laisser passer, (dejar hacer, el dejar pasar), esta sentencia propugnaba por una mínima intervención del Estado en la economía, que solo se debía intervenir ante crisis demasiado severas. Como se ha señalado en la literatura un Estado mínimo. Esta fórmula era el resultado de los postulados económicos del momento que confiaban en la mano invisible del mercado, en que los defectos del capital se corrigen solos con la proliferación de la riqueza.
\end{abstract}

Estamos en un momento puntual para las relaciones financieras y comerciales, que veían con desconfianza a las prerrogativas del modelo antecesor el Estado absoluto, algo así como una reacción de los capitales ante lo que ellos creían el Estado era un órgano ilimitado que restringía a las libertades económicas, pero que al hacerlo caía en un reduccionismo maniqueo ya que al intentar limitar al Estado a funciones básicas como la legislativa, la jurisdiccional, la ejecución de las sentencias, la protección de las seguridades exteriores e internas, el recrudecimiento de la identidad del Estado-Nación, como oponente de lo externo, se reducía las oportunidades que el Estado tiene como rector de la economía para permitir que todos los integrantes de la sociedad participen de los asuntos públicos, lo que para Jorge Fernández Ruiz se concretaba en la preferencia por una clase de Estado, de Estado policía que:

"(...) se trataba de un Estado policía, caracterizado por su individualismo que privilegia al sujeto sobre todo aspecto social o colectivo; por la libertad que incluye la de explotar a los demás; por la postulación del Estado de Derecho, así como por el reconocimiento de los derechos y libertades políticas de los ciudadanos" (Fernández 2006, 26).

Aun cuando la preferencia del capital era el Estado policía, la naturaleza del Estado de Derecho es muy compleja, porque en ella inciden el papel de los derechos como precondiciones de igualdad y libertad, el derecho requiere de técnicas para que estas puedan extenderse a todos los integrantes de la sociedad lo que no basta con la simple declaración de ellos, Luciano Parejo
Alfonso critica esta doble naturaleza del Estado de Derecho, que se puede ver así, por un lado se conceden derechos abstractos e impersonales para todos, pero si no se ponen las condiciones claras para el disfrute de ellos, el derecho termina siendo solo un instrumento del capital, de quien tiene poder político o económico para la certeza de sus actos: "(...)lo importante es que, para el Derecho, todos tengan iguales derechos, con independencia de que no estén realmente en situación de disfrutarlos y ejercitarlos por igual incurriendo en el riesgo de que la igualdad formal de todos se convierta en el derecho de los más poderosos de hacer valer sin contemplaciones su superioridad real" (Parejo 1984, 181). Es así que se observan las interesantes pugnas en esta primera etapa del Estado de Derecho que enfocado en el liberalismo económico, en dar certeza al capital, continuaba preservando un esquema de dominación y opresión para los sectores desfavorecidos de la sociedad moderna.

Este incipiente carácter garantista de los derechos fundamentales en el Estado de Derecho es la causa que motiva la subsecuente transfiguración de propio Estado. La insuficiencia del Estado de Derecho para poder abordar con propiedad el conflicto que Norberto Bobbio percibe al observar que no se puede pensar que el Estado liberal equivale a democracia:

“(...) Un Estado liberal no es por fuerza democrático; más aún, históricamente se realiza en sociedades en las cuales la participación en el gobierno está muy limitada a las clases pudientes" (Bobbio 2002, 7).

Puede resaltarse una condición favorable del Estado de Derecho y consiste que el individuo adquiere una importancia única, porque se le reconocen derechos. El liberalismo pretende ese énfasis en el empoderamiento del individuo. Él es el principal protagonista de la sociedad, la sociedad no puede oprimirlo, porque el individuo tiene un conjunto de 
Introducción acerca de las implicaciones del Estado de derecho en su relación con el concepto de responsabilidad patrimonial Introduction about the implications of the Rule of Law in its relation to the concept of asset liability

derechos que lo protegen frente a las intenciones populistas o totalitarias de la sociedad. El conjunto de derechos son, de índole, la protección de la propiedad privada, libertades económicas para el comercio y la libre competencia. Es una respuesta justificada dado que el Estado absoluto al primar en las relaciones mercantiles oprimía las relaciones del individuo con el capital por lo que el individuo demandaba certeza a sus derechos individuales.

La fórmula del Estado de Derecho no se tradujo en pensamiento democrático, contrariamente afirma Fioravanti: "todo el derecho público europeo del cambio de siglo se afirma en oposición al principio democrático de la soberanía popular" (Fioravanti, 147). El Estado de Derecho tiene un componente muy dirigido al resguardo de los derechos individuales, de la protección de la libertad pero no equivale, como ya mencionamos a democracia, cuando citamos a Norberto Bobbio, esta apreciación también la comparte Ernst Wolfang Bockenforde:

"El concepto del Estado de Derecho incluye una tendencia hacia la libertad, pero no se inclina de forma incondicionada hacia la democracia. La libertad política de los ciudadanos, su participación activa en la vida del Estado, vale como culminación y garantía de la libertad civil, pero encuentra su límite allí donde no llega la protección de la libertad civil, donde esta se pone en peligro o, en otras palabras, donde deja de dar preferencia a la razón y se inclina a favor de los meros deseos o intereses" (Bockenforde 2000, 22-23).

El Estado de Derecho tuvo como matices negativos una preferencia de la libertad pero con un menoscabo en los intentos de democracia, no podía darse de forma amplia la participación de los ciudadanos en la vida pública, haciendo uso de sus libertades, pues estas no se protegía, esto lo que produjo fue que el derecho fuera un cúmulo de normas positivistas pero que solo aseguraban las libertades económicas y de las cuales no todos los que integraban el Estado podían beneficiarse, en este sentido Jorge Fernández Ruiz expresa que las tesis liberales individualistas elaboradas por los fisiócratas franceses entre ellos un visible Francisco Quesnay y la tesis del Homo œeconomicus como era entendida por Adam Smith formularon la connivencia del Estado de Derecho con los postulados del liberalismo económico, encontrando asiento para robustecer el mercado, la libre empresa y el individualismo. Estas doctrinas tienen sus aciertos pero también han causado un esquema en el que prevalece el interés económico como fin de las relaciones sociales y productivas. Desechando a las personas que han sido incapaces o no han tenido las oportunidades para beneficiarse del mercado.

El Estado de Derecho tiene otro acierto que se refleja en la limitación del Estado ante las normas, la sujeción del poder público al derecho, que se manifiesta entre otros principios, por el principio de legalidad. Esto conlleva a que el Estado de Derecho sea marcadamente un gobierno de leyes y no un gobierno de personas. La personalidad siempre estará presente pero las leyes conllevan el resultado de arreglos formales, arreglos institucionales que son más acordes a los postulados del pensamiento racional europeo, al respecto Norberto Bobbio recapitula esta experiencia:

"(...) El respeto a la ley le impide al gobernante ejercer parcialmente su poder en defensa de intereses privados, de las mismas maneras que las reglas del arte, de la medicina, bien aplicadas, impiden a los médicos tratar de diferente manera a sus pacientes de acuerdo al criterio de que sean amigos o enemigos. Mientras la primacía de la ley protege al ciudadano del arbitrio del mal gobernante, la superioridad del hombre lo protege de la aplicación indiscriminada de la norma general, bajo el supuesto de que el gobernante sea justo" (Bobbio 2003, 169-171).

Son dos aspectos que no pueden desprenderse: la primacía de la ley, que debe prevalecer, y el papel que desempeña el hombre para aplicar las normas. Esto conlleva a planteamientos éticos, morales y humanistas. En las sociedades, siempre la organización del poder político tendrá que depender de sus condiciones de legitimación. Además, de los esquemas de sujeción y 


\section{Luis Gerardo Rodríguez Lozano y Talia Garza Hernández}

colaboración entre las distintas clases sociales que integran la sociedad y la división del trabajo y del capital. El Estado de Derecho es un modelo que intenta conciliar el papel que tiene el hombre y la ley para esa organización social, el gobierno de los hombres indiscutiblemente apareja concentración del poder político en la persona o en el grupo dominante, la ley en el Estado de Derecho racionaliza ese proceso por los arreglos (acuerdos) conforme a procedimientos racionales: elecciones, asambleas, sistema disciplinario y de responsabilidades.

El Estado de Derecho no será la etapa final, su aportación de la limitación de la concentración del poder político por la ley de acuerdo a acuerdos racionales con procedimientos formales, materializados por la ley, conlleva a un cambio de la posición privilegiada del gobernante a la posición del individuo, instrumentalizada por sus derechos individuales, de los que de destacan la propiedad privada y las libertades económicas. Pero sobresale mucho que empieza a figurarse que los gobernantes no son infalibles, que tienen que ser sometidos a un sistema de disciplinario y de responsabilidades, el papel de la democracia, en tal situación Bobbio comenta que la democracia es un sistema de reglas:

\begin{abstract}
"Si para concluir el análisis se me pide quitarme la vestimenta de estudioso y ponerme la del hombre comprometido con la vida política de su tiempo, no tengo ningún empacho en decir que prefiero el gobierno de las leyes y no el de los hombres. El gobierno de las leyes celebra hoy su triunfo en la democracia. ¿Qué cosa es la democracia sino un conjunto de reglas (las Ilamadas reglas del juego) para solucionar los conflictos sin derramamiento de sangre? ¿En qué consiste el buen gobierno democrático, si no, y sobre todo, en el respeto riguroso de estas reglas? Personalmente, no tengo dudas sobre la respuesta a estas preguntas; y precisamente porque no tengo dudas puedo concluir tranquilamente que la democracia es el gobierno de las leyes por excelencia. En el mismo momento en el que un régimen democrático pierde de vista este principio inspirador que le es propio, cambia rápidamente en su contrario, en una de las tantas formas de gobierno autocrático, del que están llenas las narraciones de los historiadores y las reflexiones de los escritores políticos" (Bobbio 2003, 189).
\end{abstract}

\subsection{El Estado de Bienestar}

Aun cuando el desarrollo del Estado de Derecho constituye un elevado avance en relación con la posición del individuo frente a la posición del gobernante, quedaba un tercero en duda: la sociedad. ¿Cómo conciliar a estos tres entes? Si el Estado frecuentemente era cuestionado por su opresión del individuo, acaso también podía ¿oprimir a la sociedad? Acaso, ¿los actos del individuo podían ser contrarios a la sociedad? La fórmula del Estado de Bienestar procura conciliar estas profundas contradicciones dentro del capitalismo y por ello tienen sus limitaciones. El Estado de Derecho no significaba democracia, pero sí libertad. Pero la Revolución Francesa de 1789, con su fórmula ideológica de Libertad, Igualdad y Fraternidad, quiso hacer pensar que ello era posible. No cabe duda que la libertad y la igualdad engendran cierta antinomia y que tienen diferencias también en relación con la fraternidad o la solidaridad. Pero los avances del liberalismo económico seguían sin resolver cuestiones de desigualdad y distribución del trabajo y del capital que germinaron en la fórmula del Estado de Bienestar.

Ya mencionamos que en la comunidad política la antinomia entre libertad e igualdad está latente, hay quienes prefieren la primera, es decir, que el Estado se decante por la protección de la libertad negativa, que solo requiere de la ley, no de actuaciones activas del Estado para asegurarla. El Estado tiene que ser mínimo, actor pasivo que no se dedique a redistribuir, pero esto alimenta solo más indignación, pues el Estado renuncia a su papel como agente de equidad social, en:

"(...) reconocer a todos los individuos un derecho a la propiedad, o libertad de trabajo, o de enseñar y aprender, si las condiciones socioeconómicas imperantes (miseria, enfermedad, accidentes, ignorancia, vejez) excluyen permanentemente a algunos individuos toda oportunidad de ser propietarios, trabajar libremente, o aprender y enseñar. Esta es la paradoja que el Estado de 


\section{Introducción acerca de las implicaciones del Estado de derecho en su relación con el concepto de responsabilidad patrimonial Introduction about the implications of the Rule of Law in its relation to the concept of asset liability}

Derecho, en un planteo muy tradicional, no había podido al parecer superar" (Gordillo 2013, 68).

El liberalismo económico tuvo su auge en la Revolución Industrial, ante tan expansiva actividad industrial Inglaterra empezó a modificar sus estructuras administrativas para corregir ciertas desigualdades que provocaban inestabilidad y demandas por parte de la clase obrera. El Estado empieza a aumentar su participación en la vida civil, empiezan las primeras manifestaciones de servicios sociales.

El liberalismo económico desde el año de 1815 al año 1848 tiene una importante evolución, las dos guerras mundiales se dan en contextos problemáticos de expansión del capital y entronización del Estado-Nación. Después de la Segunda Guerra Mundial, los Estados-Nación más desarrollados echaron a andar la maquinaria del Estado social para generar incentivos para la clase trabajadora y procurar la paz social. El Estado social se articula como un principio.

Hay obviamente intenciones políticas y de lucha de poderes entre los Estados-Nación desarrollados como Jorge Fernández Ruiz apunta con inteligencia:

"(...) arrebatar las banderas del movimiento comunista desarrollado a partir del Manifiesto del Partido Comunista Redactado por Carlos Marx y Federico Engels en 1848, por la Primera internacional, para dar lugar al surgimiento del Estado de Bienestar o Welfare State, basado en el solidarismo" (Fernández 2006, 29).

Más allá de la lucha entre el sistema capitalista y comunista, los logros fueron sustanciales pues se logró avanzar hacia la construcción de sociedades más igualitarias, extender la protección y garantía de derechos sociales hacia grupos tradicionalmente desfavorecidos, que más personas pudieran acceder a los servicios sociales y salir de la pobreza. La fórmula del Estado social pretendía trascender de la igualdad formal a la igualdad material como condición para la garantía de los derechos fundamentales de los ciudadanos del Estado por medio de los instrumentos que proveen el principio de igualdad y el principio de solidaridad.

En el Estado de Derecho, la garantía de los derechos de los ciudadanos se depositaba en la declaración de la igualdad formal en los textos constitucionales. Por consiguiente, los deberes de las administraciones públicas se fueron acrecentando para satisfacer los servicios sociales como la seguridad social, los derechos laborales, satisfacción de los derechos de las personas en situación de dependencia, tutela de los servicios públicos básicos (alumbrado público, agua potable, mantenimiento de los cementerios, servicio de transporte público, telecomunicaciones, vías férreas y carreteras, etcétera). Ante esta nueva realidad en la que la administración tiene un conjunto muy amplio de deberes, las teorías del solidarismo contribuirán sustancialmente para la legitimación del principio del Estado social como eje articulador del Estado Liberal Democrático y Social de Derecho. Una clara transformación del reductor esquema de su antecesor el Estado policía.

Mientras el Estado policía se limita a preservar el poder y su legitimidad, una visión de Estado en la que prevalece la potestad policial. El Estado social tiene, como se sabe, un fuerte carácter interventor que pretende corregir desigualdades sociales e históricas, redistribución de la riqueza y acentuación en la justicia social. La administración tiene que racionalizarse y reorganizarse, tiene que someterse a la ley, tiene como límite los derechos del ciudadano, las teorías del solidarismo hacen su aportación.

Nociones como el interés público y el bien común serán puestas en discusión por los partidarios del solidarismo, el concepto de solidarismo es el eje que legitima esta fórmula del Estado social, el ente social tiene vida propia y requiere de la colaboración y del compromiso de los individuos, no puede menoscabarse o tratarse como si fuera ajena al individuo:

"Solidarismo es aquel sistema de ordenación social que, frente a las doctrinas unilaterales del individualismo y del colectivismo, hace justicia al doble 


\section{Luis Gerardo Rodríguez Lozano y Talia Garza Hernández}

aspecto de la relación entre individuo y sociedad; así como el individuo ésta ordenado a la comunidad en virtud de las disposiciones para la vida social ínsita en su naturaleza, la comunidad se halla ordenada a los individuos que le dan el ser, en el cual y por los cuales exclusivamente existe (...) cada cual ha de responder por el todo; el todo ha de responder por cada uno de sus miembros. Característico del solidarismo es su concepto del bien común y la posición dominante que le asignen" (Fernández 2006, 29-30)(10).

El Estado social o sus acepciones de Estado de Bienestar y Welfare State pretende corregir desigualdades, fomentar el bienestar de la sociedad, tienen como instrumentos los servicios públicos, los servicios sociales y la política social. Para poder concretar sus medidas tiene que formular un elevado sistema de planeación, planificación y asignación de recursos. Este modelo requiere de un carácter intervencionista del Estado en la economía y paradójicamente esto provocará sus ulteriores crisis en la denominada crisis del Estado de Bienestar que tuvo lugar en Europa a partir de la década de los noventa y ahora en el siglo XXI. Si bien sus aportes aún no han desaparecido porque "toda la problemática del Estado social está vinculado a corregir la desigualdad" (Sotelo 2010, 48).

\subsection{El Estado Neoliberal}

Es inabarcable todo lo que se ha escrito sobre la crisis del Estado de Bienestar y coincidente en que esta se produjo ante las intervenciones desmedidas del Estado en la economía y el engrosamiento de la deuda pública. Esto se observó con los países que fueron satélites de la extinta Unión Soviética, los países ex comunistas de la de Europa del Este que una vez que transitaron a la democracia capitalista han incorporado las políticas neoliberales para salir de sus respectivas crisis económicas y sociales y poder resarcir las necesidades de sus poblaciones. El marco de las políticas neoliberales ha sido respaldado por el Consenso de Washington, que ha promovido medidas neoliberales impulsadas por organismos financieros internacionales y regionales como el Banco Mundial y el Fondo Monetario Internacional, el Banco Interamericano de Desarrollo, quienes proponen que los Estados tienen que sujetarse a lineamientos como la desregulación de los mercados, la privatización de las empresas públicas y de los bienes públicos, la promoción de la libre competencia y el mantenimiento de una disciplina presupuestaria con las políticas de austeridad. Evidentemente, es una reacción ante un Estado obeso y corrupto pero con un costo social altísimo, porque el cambio de manos no ha sido más transparente ni menos corrupto (Llistar 2003).

Merece la pena añadir que los países en el modelo de Estado Neoliberal son muy dependientes, más de lo que el ciudadano común puede reconocer, de los centros del poder financiero internacional, paradójicamente ellos perciben que en esa dependencia esta su seguridad, el margen de maniobra que tienen los gobernantes es mínimo porque el verdadero poder económico reside en las empresas trasnacionales. Con la aplicación de políticas ortodoxas que tranquilicen a los mercados y favorezcan la inversión en la que los riesgos los asuman el capital privado pero con ventajas mínimas para Estados débiles dependen de un financiamiento internacional condicionado por la liberalización y desregulación de los mercados y de sectores de la economía que son estratégicos para la economía de las naciones.

Las tendencias de la globalización económica dirigidas por los organismos financieros internacionales y las economías desarrolladas son una realidad que tenemos que enfrentar y sobrevivir a ella, son una consecuencia de posiciones de poder, de pugnas ideológicas internacionales; ante esta realidad era inevitable que el Estado-Nación comenzará a perder terreno decisorio, sobre lo cual Oriol Mir Puigpelat expone que la gradual pérdida que los Estados-Nación han enfrentado en los últimos decenios, ocurriendo que sean las poderosas corporaciones trasnacionales las que concentran el poderío económico, político y social e inclusive jurídico, pues no solo concentran una enorme influencia en las legislaturas nacionales, sino que

(10) Citado por Nell Breuning, Oswald Von, "Solidarismo". 
Introducción acerca de las implicaciones del Estado de derecho en su relación con el concepto de responsabilidad patrimonial Introduction about the implications of the Rule of Law in its relation to the concept of asset liability

además encabezan y aprueban de facto las normas y también los tribunales que regulan y resuelven las relaciones económicas conocidas, agrega que estas con conocidas como lex mercantoria así como las disputas comerciales que se realizan entre los diferentes agentes económicos que intervienen en los procesos económicos ya globalizados. Estos órganos no estatales de resolución de conflictos, explica Oriol Mir Puigpelat, son los órganos ante los cuales los agentes económicos trasnacionales prefieren presentar sus disputas de índole económica y comercial, manifestándose así un efecto de la globalización y del derecho ya abordado en el primer apartado de este capítulo, pues es el derecho el que tiene que ser adaptado para responder a los intereses empresariales (Mir Puigpelat 2004, 39-40). Oriol Mir Puigpelat manifiesta que temerosos de perder inversiones, los gobiernos capitulan ante los empresarios.

En un enfoque intermedio, es comprensible que los gobiernos quieran favorecer la inversión económica para generar mayores fuentes de empleo, mejores salarios, ingresos públicos, etcétera, solo que la paradoja en las transfiguraciones del Estado se ha avivado proyectándose en la distribución de la riqueza. La disciplina fiscal y el saneamiento de las finanzas públicas, los dictados para el manejo de la contratación de deuda pública son afianzados por un sistema financiero internacional e instituciones de gobernanza que han legitimado los predicamentos del neoliberalismo. Pero el modelo de austeridad ha sido cuestionado crecientemente. Ante esa situación, el Derecho puede ofrecer soluciones novedosas.

El Consenso de Washington y sus políticas neoliberales apoyadas por los organismos financieros internacionales y los países y sus clases políticas y élites económicas, ha comenzado a mostrar sus limitaciones, su incapacidad para reorganizar la distribución de la riqueza y corregir la desigualdad, Cesáreo Morales ejemplifica algunas de las consecuencias negativas del modelo neoliberal y de sus políticas y directrices:

"Queda la parafernalia sacrificial de la globalización, que demanda cada año la muerte de 11 millones de niños menores de cinco años por desnutrición o falta de servicios sociales de salud, los miles de millones de desempleados con su desesperación y su furia, los campesinos del mundo y su impaciencia, los indígenas de todas las etnias y su testimonio. No sabemos ante que dios tiene lugar esa inmolación, ni porque ese ritual de lo inhumano celebrado en el monte Moriah desgajado, en el que Abraham desaparece en medio de un grito interminable y el silencio. Queda una economía que impone la muerte y una sociedad del desperdicio que ataca a la mayoría, como si cumplieran un mandato secreto incuestionable, como si estuvieran obligadas a demostrar a sí mismas su fuerza de autodestrucción y arbitrariedad infinita, su locura perversa y sin control, aunque se cubran pudorosamente con el discurso de la eficiencia y la competitividad. Queda la teología política del día a día de la desesperanza en el desierto, el día a día del desastre" (Morales 2010, 117-118).

No es posible para la doctrina prever el fin de un modelo, sino observar, discutir y criticar los signos de la decadencia de los conceptos de estudio en su campo de estudio, en este caso particular en lo que concierna al derecho y su relación con el estado neoliberal, parte del análisis exige verlo como un estudio, con distancia, el modelo neoliberal tuvo sus razones, no nos proponemos enjuiciarlo, pues se trata de una etapa en la transformación del Estado moderno en su evolución hacia la constitución de un sistema disciplinario y de responsabilidades. El Estado de Derecho ha atravesado por diversas etapas y esta es una de ellas, ciertamente que sucedió como una reacción ante los logros y, por qué no decirlo, desaciertos del Estado de Bienestar, consiguientemente estamos de acuerdo con el razonamiento de Jorge Fernández Ruiz quien de forma premonitoria avista el inevitable desgaste de este modelo de Estado:

"La reacción neoliberal hoy triunfante en la conformación del Estado contemporáneo, más temprano que tarde habrá de desgastarse, como ocurrió con los movimientos que le precedieron en el afán configurativo del ente estatal; porque no 


\section{Luis Gerardo Rodríguez Lozano y Talia Garza Hernández}

puede perpetuarse un esquema que en aras de la libertad de enriquecimiento insultante de unos pocos, arroja a los abismos del desempleo, la ignorancia, la insalubridad, la miseria y la hambruna a millones de seres humanos, que de esta suerte ven cancelada la posibilidad de una vida digna al no poder disfrutar sus Derechos Humanos Económicos, Sociales y Culturales" (Fernández 2006, 30).

Así como en su momento el modelo de Estado social canalizó demandas legítimas, aun cuando se justificaba en un entorno internacional conflictivo. El anhelo de una sociedad justa y de valores coadyuvará para poder encontrar un equilibrio en el orden social y jurídico. El derecho tiene como objeto cada vez más presente a la persona humana como centro del ordenamiento jurídico.

\section{Carácter constitucional de la responsabilidad patrimonial del Estado}

El principio de la responsabilidad patrimonial del Estado fue consagrado en el artículo 113 de la Constitución Política de los Estados Unidos Mexicanos. Esta institución debe analizarse en correlación con el principio de legalidad, pues ambos constituyen como afirma Castro Estrada "pilares del Derecho Administrativo" (Castro 2006, 255).

En el derecho comparado, la constitucionalización del principio de responsabilidad patrimonial del Estado no puede verse como la elevación a jerarquía constitucional de un principio, por supuesto que significa una evolución en materia de Estado Constitucional, recordemos el principio de responsabilidad que menciona Peter Häberle (Häberle 2003, 7), pero esto ha provocado algo mucho más coherente, es una significación, que de acuerdo a Castro Estrada conforma "un auténtico sistema de garantía patrimonial de los administrados". Mas ello solo tiene validez cuando se desenvuelvan ciertos requisitos que deban corresponder a un sistema disciplinario y de responsabilidades. Es decir, como en los ordenamientos liberales (Vergottini 2004, 45)(11), la Constitución es norma suprema.

En efecto, existen diferentes clases de constituciones como la Constitución histórico-tradicional o la racional normativa, en cada una de estas debe estar implantado este sistema de responsabilidad disciplinaria y de responsabilidades del Estado. En consecuencia, la superioridad del ordenamiento y la relación de jerarquía que las normas del ordenamiento guardan con el ordenamiento jurídico es la que implica esta significación de lo constitucional. Aunque esta concepción se encuentra enfrentada con el pluralismo normativo, por eso la Constitución irradia con sus principios y valores el ordenamiento jurídico. En este sentido el carácter constitucional de la institución de la responsabilidad patrimonial del Estado despliega el diseño de esta institución.

En efecto, la responsabilidad patrimonial del Estado es una garantía constitucional de los administrados, así la califica la doctrina; por ejemplo, mencionamos a Álvarez Ortiz para obtener reparación por los perjuicios causados por las autoridades administrativas (Ortiz 2006, 362). En el marco constitucional, el fundamento de esta institución fue legislado en el artículo 109. No obstante, la doctrina ha reconocido que este instituto ha tenido una tardía y progresiva incorporación al marco jurídico mexicano ${ }^{(12)}$.

\subsection{El difícil desenvolvimiento de la} responsabilidad patrimonial del Estado Una de las dificultades más relevantes para la consolidación de esta institución de responsabilidad patrimonial del Estado en México consiste, para Castro Estrada, en la tradición de nuestro sistema "jurídico-social" (Castro 2006, 89), que ha entronizado muy rígidamente la figura del juez. Y Castro Estrada argumenta una razón muy lógica acerca de tales dificultades: "(...) sabemos que como el ser humano está expuesto a equivocarse y, aunque pese a algunos reconocerlo, el propio sistema procesal reconoce la posibilidad de errores en la actuación jurisdiccional, al establecer una serie de recursos judiciales que son necesarios para enmendar apreciaciones jurídicas, muchas veces equivocadas" (Castro 2006, 89).

(11) Nos referimos al estado de derivación liberal, tipología planteada por Giuseppe de Vergottini. 
Introducción acerca de las implicaciones del Estado de derecho en su relación con el concepto de responsabilidad patrimonial Introduction about the implications of the Rule of Law in its relation to the concept of asset liability

El sistema procesal es una variable que tiene sus propios mecanismos y comportamientos, la introducción e innovación de nuevas instituciones jurídicas y procesales tienen que lidiar con ello, lo cual Atienza describe en un sentido todavía más amplio, por la influencia que tiene el Derecho en la evolución de las relaciones de la sociedad con el derecho:

"las sociedades pueden hacerse, en diversos sentidos, más complejas sin que ello signifique que son más justas; la mayor presencia del Derecho, de instrumentos jurídicos, para gobernar la conducta de los hombres en la sociedad no lleva necesariamente aparejado un orden social de tipo superior" (Atienza 2001, 20).

Sin duda, es este uno de los paradigmas que más se han problematizado en el derecho, porque subrayan en el papel de la ley, como intérprete o como simple repetidor de la ley. Si el paradigma formalista resaltaba el papel de la ley, el paradigma de la interpretación de los sistemas del common law prefería la interpretación jurisdiccional, lo cual era proclive al papel del juez. ¿Pero cuánta interpretación puede soportar el Derecho sin ser víctima de su propia disgregación interpretativa? En esto reposa la relevancia de esta institución para el Estado Constitucional. Dado que la responsabilidad patrimonial del Estado es un gran sistema que no se circunscribe únicamente al orden jurisdiccional, por ello suscribimos la clasificación tripartita de Castro Estrada de responsabilidad de Estado-juez; responsabilidad de Estado-legislador y la responsabilidad del Estado administrador, todas ellas inmersas en el sistema de responsabilidad estatal (Castro 2006, 89).

Aunado a lo anterior, la institución de la responsabilidad patrimonial del Estado se enfrenta a la propia resistencia de las administraciones públicas por quienes alegan limitaciones presupuestales, Blanquer suscribe este sentir en la corriente tendencia de asemejar al Estado de bienestar "con la existencia de un seguro a todo riesgo" (Blanquer 1997, 22). Situación que justificadamente menciona Blanquer ha sido superada gracias al propio diseño doctrinal y riguroso de esta institución (Blanquer 1997, 20).

\subsection{La responsabilidad patrimonial del Estado y su impacto en el sistema jurídico mexicano}

Delgadillo Gutiérrez distinguió como el más significativo de los logros en la institucionalización de la institución de la responsabilidad patrimonial del Estado, su adopción por conducto de la reforma constitucional al artículo 113, publicada en el Diario Oficial de la Federación, el 12 de junio del año 2002, constitucionalizó la responsabilidad objetiva y directa del Estado por actividad administrativa irregular que cause daños a los particulares (Delgadillo 1995). El fundamento constitucional citado fue transferido al artículo 109 del ordenamiento supremo a raíz de la reforma constitucional publicada en el Diario Oficial de la Federación, el 27 de mayo del año 2015 que reorganizó el sistema de la responsabilidad estatal, cuyo marco normativo está consagrado el título cuarto, de nuestra norma fundamental que se titula: De las responsabilidades de los servidores públicos, particulares vinculados con faltas administrativas graves o hechos de corrupción, y patrimonial del Estado(13).

El impacto de esta institución en el sistema jurídico mexicano desde el punto de vista formal se concentra en su marco constitucional,

(12) Véase Manuel Lucero Espinosa, Responsabilidad patrimonial del Estado en el ámbito federal (México: Espress, 2015$), 41$. "La regulación de la responsabilidad del Estado ha tenido una evolución muy lenta en nuestro país; es más, actualmente no hemos llegado al total reconocimiento de la responsabilidad en que puede incurrir el Estado por daños y perjuicios que causen las autoridades en ejercicio de su actividad, ya que sólo la responsabilidad patrimonial del Estado opera por una actividad administrativa irregular pero no por ésta cuando sea regular y mucho menos en materia legislativa o judicial, como sucede en otros países".

(13) Decreto por el que se reforman, adicionan y derogan diversas disposiciones de la Constitución Política de los Estados Unidos Mexicanos, en materia de combate a la corrupción. DOF: 27/05/2015, consultar: http://www.dof.gob.mx/nota_detalle. php? codigo $=5394003 \&$ fecha $=27 / 05 / 2015-$. 


\section{Luis Gerardo Rodríguez Lozano y Talia Garza Hernández}

en su ordenamiento específico en el ámbito federal que es la Ley Federal de Responsabilidad Patrimonial del Estado, las legislaciones en el ámbito local, así como en sus reformas. Además, el impacto de esta institución también se refleja en la interpretación de esta institución por los jueces, pues la interpretación del juez es uno de los paradigmas del sistema jurídico mexicano que ha retardado la consolidación de la justicia administrativa.

\section{Referencias Bibliográficas}

Anderson, Perry. 1990. El estado absolutista. 11a ed. Traducido por Juliá De Santos. México: Siglo XXI.

Atienza, Manuel. 2001. El sentido del derecho. Barcelona: Ariel.

Bastida, Francisco; Varela, Joaquín y Juan Luis Requejo. 2008. Derecho constitucional. Cuestionario comentado, I. Teoría de la constitución, principios estructurales, órganos y funciones constitucionales. $4^{\mathrm{a}}$ ed. Editorial Ariel

Blanquer, Daniel. 1997. La responsabilidad patrimonial de las administraciones públicas. Madrid: Instituto Nacional de Administración Pública.

Bobbio, Norberto. 1975-1976. La teoría de las formas de gobierno en la historia del pensamiento político. $2^{\text {a }}$ ed. Traducido por José F. Fernández Santillán. México.

2002. Liberalismo y democracia. 8 ed. Traducido por José Francisco Fernández Santillán. México: Fondo de Cultura Económica.

2003. El futuro de la democracia. 3a ed. Traducido por José Fernández Santillán. México: Fondo de Cultura Económica.

Bockenforde Wolfang, Ernst. 2000. Estudios sobre el Estado de derecho y la democracia. Traducido por Rafael de Agapito Serrano. Madrid: Trotta.

Castro Estrada, Álvaro. 2006. Responsabilidad patrimonial del Estado. 3ạ ed. México: Porrúa.
Cassese, Sabino. 2010. Los tribunales ante la construcción de un sistema jurídico global. Sevilla: Derecho Global.

2014. Derecho administrativo: Historia y futuro, Madrid: Global Law Press. INAP

Celdrán Ruano, Julia. 1996. La responsabilidad del estado por actos de aplicación de leyes: aproximación histórica y significado actual. Murcia: Universidad de Murcia.

Châtelet, François. 1980. Historia de las ideologías. Tomo II. Traducido por Luis Pasamar. México: La Red de Jonás.

Crossman, R.H.S. 1978. Biografía del Estado moderno. 3a ed. Traducido por J. A. Fernández de Castro. México: Fondo de Cultura Económica.

Delgadillo Gutiérrez, Luis Humberto. 1995. La responsabilidad patrimonial del Estado mexicano. Revista de Administración Pública, Reflexiones sobre administración pública 89.

2010. Elementos de derecho administrativo primer curso. 3a ed. México: Limusa.

De Vergottini, Giuseppe. 2004. Derecho constitucional comparado. Traducido por Claudia Herrera. México: Universidad Nacional Autónoma de México.

Fernández Ruiz, Jorge. 2006a. Derecho administrativo y administración pública. México: Porrúa.

2006b. Derecho administrativo y administración pública. México: Porrúa.

Fioravanti, Maurizio. Constitución: De la antigüedad a nuestros días. Traducido por Manuel Martínez Neira. Madrid: Trotta. 
Introducción acerca de las implicaciones del Estado de derecho en su relación con el concepto de responsabilidad patrimonial Introduction about the implications of the Rule of Law in its relation to the concept of asset liability

García de Enterría, Eduardo. 2001. La constitución como norma y el tribunal constitucional. 3a ed. Madrid: Civitas.

Gordillo, Agustín. 2013. Tratado de Derecho Administrativo y obras selectas: Teoría general del Derecho Administrativo. 2a ed. Tomo 8. Buenos Aires: Fundación de Derecho Administrativo.

Häberle, Peter. 2000. El estado constitucional europeo. Cuestiones constitucionales 2. (enero-junio): 87-104.

2003. El Estado constitucional. 2a ed. Traducido por Héctor Fix-Fierro. México: Universidad Nacional Autónoma de México.

Habermas, Jürgen. 1999. Más allá del Estado nacional. $2^{\mathrm{a}}$ ed. Traducido por Manuel Jiménez Redondo. México: Fondo de Cultura Económica.

Künnecke, Martina. 2007. Tradition and change in administrative law. An AngloGerman comparison. New York: Springer. doi:10.1007/978-3-540-48689-3_6.

Llistar, David. 2003. Introducción El consenso de Washington una década después. En El fracaso del consenso de Washington. La caída de su mejor alumno: Argentina, coord. Laura Ramos. Barcelona: Icaria.

Maquiavelo, Nicolás. 2010. El príncipe. 26a ed. Traducido por Antonio Gómez Robledo. México: Porrúa.

Martín Jiménez, Luis Carlos. 2014. El valor de la axiología. Crítica a la idea de valor y a las teorías y doctrinas de los valores. Oviedo: Pentalfa Ediciones.

Martínez Martínez, Faustino. 2010. Literatura y Derecho. México: Universidad Nacional Autónoma de México.
Marx, Karl y Frederich Engels. 2009. Sobre el arte. Traducido por Ana Drucker, Buenos Aires: Claridad.

Meilán Gil, José Luis. 2011. Una aproximación al derecho administrativo global. Sevilla: Derecho Global.

Mir Puigpelat, Oriol. 2004. Globalización, Estado y Derecho. Las transformaciones recientes del derecho administrativo. Madrid: Civitas.

Morales, Cesáreo. 2010. ¿Hacia dónde vamos? México: Siglo veintiuno.

Ortiz Álvarez, Luis. 2006. Responsabilidad patrimonial de la administración en Venezuela. En Badell Madrid, Rafael. Congreso internacional de derecho administrativo. En homenaje al Profesor Luis Farías Mata. Caracas: Universidad Católica Andrés Bello.

Parejo Alfonso, Luciano. 1984. El concepto del derecho administrativo. Caracas: Editorial Jurídica Venezolana.

Poulantzas, Nicos. 2001. Poder político y clases sociales en el Estado capitalista. 29a ed. México: Siglo XXI Editores.

Serra Rojas, Andrés. 1972. Derecho administrativo. Doctrina, legislación y jurisprudencia. $5^{\mathrm{a}}$ ed. Tomo II. México: Impresora Galve.

Skinner, Quentin. 2003. El nacimiento del Estado. Traducido por Mariana Gaiza. Ciudad Autónoma de Buenos Aires: Gorla.

Sotelo, Ignacio. 2010. El Estado social. Madrid: Trotta.

Valadés, Diego. 2010. Galileo y el Estado. En Rodríguez Jorge, Luis Felipe y Silvia Torres Castilleja (compiladores). Galileo su tiempo, su obra y su legado. México: El Colegio Nacional.

Weber, Max. 2002. Economía y sociedad. Esbozo de sociología comprensiva. $2^{\mathrm{a}}$ ed. Traducido por José Medina Echavarría, Juan Roura Farella, Eugenio Ímaz, Eduardo García Máynez y José Ferrater Mora. Madrid: Fondo de Cultura Económica.

Zagrebelsky, Gustavo. 2011. El derecho dúctil. Ley, derechos, justicia. 10a ed. Traducido por Marina Gascón. Madrid: Trotta. 